\title{
Revision of 'Balaena' belgica reveals a new right whale species, the possible ancestry of the northern right whale, Eubalaena glacialis, and the ages of divergence for the living right whale species
}

\author{
Michelangelo Bisconti ${ }^{\text {Corresp., }}{ }^{1}$, Olivier Lambert ${ }^{2}$, Mark Bosselaers ${ }^{2,3}$ \\ ${ }^{1}$ San Diego Natural History Museum, San Diego, U.S.A. \\ 2 Royal Belgian Institute of Natural Sciences, Brussels, Belgium \\ 3 Zeeland Royal Society of Sciences, Middelburg, The Netherlands \\ Corresponding Author: Michelangelo Bisconti \\ Email address: michelangelobisconti@gmail.com
}

In 1941, O. Abel established Balaena belgica based on a series of fused cervical vertebrae and citing other cranial fragments from the late Neogene of the Antwerp harbor (northern Belgium). Later, Plisnier-Ladame and Quinet (1969) added a neurocranium and other skeletal remains from the same area to this species. Recently, the neurocranium was reassigned to the genus Eubalaena thanks to newer phylogenetic analyses. Here, a new description is provided of materials previously assigned to 'Balaena' belgica together with taxonomic revisions. Our work suggests that the cervical complex originally designated as the type of 'Balaena' belgica is too poorly preserved to be used as such and is assigned to Balaenidae gen. et sp. indet., thus making 'Balaena' belgica a nomen dubium. In addition to the neurocranium, the other remains consist in a fragment of maxilla assigned to Balaenidae gen. et sp. indet. and in a humerus assigned to Eubalaena sp. Discovered in the Kruisschans Sands Member of the Lillo Formation (3.2-2.8 Ma, Piacenzian, Late Pliocene), the neurocranium is designated as the holotype of the new species Eubalaena ianitrix. Our phylogenetic analysis supports a sister-group relationship of $E$. ianitrix and $E$. glacialis, and helps constraining the ages of origin for balaenid clades. Ecological and phylogenetic data suggest that $E$. ianitrix may represent the direct ancestor of $E$. glacialis, the latter having evolved through phyletic transformation including body size increase during the temperature decline of the Late Pliocene. 
1 Revision of 'Balaena' belgica reveals a new right whale species, the possible

2 ancestry of the northern right whale, Eubalaena glacialis, and the ages of

3 divergence for the living right whale species

4

5 Michelangelo Bisconti, ${ }^{1}$ Olivier Lambert ${ }^{2}$ and Mark Bosselaers ${ }^{2,3}$

6

7 1San Diego Natural History Museum, Balboa Park, 1788 El Prado, San Diego, CA 92101, USA

$8 \quad{ }^{2}$ Royal Belgian Institute of Natural Sciences, Rue Vautier 29, 1000 Brussels, Belgium

$9{ }^{3}$ Zeeland Royal Society of Sciences, Middelburg, The Netherlands

11 Corresponding Author

12 Michelangelo Bisconti

13 Email address: michelangelobisconti@gmail.com 
15 ABSTRACT

16

17

In 1941, O. Abel established Balaena belgica based on a series of fused cervical vertebrae and citing other cranial fragments from the late Neogene of the Antwerp harbor (northern Belgium). Later, Plisnier-Ladame and Quinet (1969) added a neurocranium and other skeletal remains from the same area to this species. Recently, the neurocranium was re-assigned to the genus Eubalaena thanks to newer phylogenetic analyses. Here, a new description is provided of materials previously assigned to 'Balaena' belgica together with taxonomic revisions. Our work suggests that the cervical complex originally designated as the type of 'Balaena' belgica is too poorly preserved to be used as such and is assigned to Balaenidae gen. et sp. indet., thus making 'Balaena' belgica a nomen dubium. In addition to the neurocranium, the other remains consist in a fragment of maxilla assigned to Balaenidae gen. et sp. indet. and in a humerus assigned to Eubalaena sp. Discovered in the Kruisschans Sands Member of the Lillo Formation (3.2-2.8 Ma, Piacenzian, Late Pliocene), the neurocranium is designated as the holotype of the new species Eubalaena ianitrix. Our phylogenetic analysis supports a sister-group relationship of E. ianitrix and E. glacialis, and helps constraining the ages of origin for balaenid clades. Ecological and phylogenetic data suggest that E. ianitrix may represent the direct ancestor of E. glacialis, the latter having evolved through phyletic transformation including body size increase during the temperature decline of the Late Pliocene. 


\section{Introduction}

Living right whales include North Atlantic, southern and North Pacific right whales, all of them grouped within the genus Eubalaena (Cetacea, Mysticeti, Balaenidae; Kenney, 2009; Rice, 2009). The North Atlantic or northern right whale obviously inhabits the North Atlantic ocean, the southern right whale is distributed in the waters around Antarctica, and the North Pacific right whale is present in a portion of the Pacific that is limited in the south by southern Japan and the southern portion of the California peninsula (Kenney, 2009). Recent studies have addressed molecular taxonomy, population dynamics, and distribution patterns of these whales suggesting that the genus Eubalena should include three species corresponding to the three groups mentioned above (namely, Eubalaena glacialis, E. australis and E. japonica) (e.g., Rosenbaum et al., 2000). Although a full agreement on this point has not been reached yet, it is largely acknowledged that North Atlantic and North Pacific right whales are suffering high extinction risk (e.g., Clapham et al., 1999). This is probably due to the catastrophic bottleneck effect induced into their populations by human hunting activities during $19^{\text {th }}$ and $20^{\text {th }}$ centuries (e.g., Gaskin, 1986) that drastically reduced the size of their populations in a brief period.

The assessment of the genetic diversity of the living right whale populations largely depends on the reconstruction of the population size before the start of industrial whaling (Rooney et al., 2001; Rosenbaum et al., 2000, Malik et al., 2000). Such a reconstruction depends on several factors including the phylogenetic history of the genus and divergence time from the living species that is phylogenetically closest to the living right whales (Rooney et al., 2001), namely the bowhead whale Balaena mysticetus. The study of the fossil record may help determining the antiquity of the 
57 genus Eubalaena and constraining the time of divergence of Eubalaena from the bowhead whale

58 (McLeod et al., 1993; Santangelo et al., 2005).

59 The fossil record of Eubalaena is scanty and scattered around the northern hemisphere. A right

60 whale skull from the Pleistocene of Japan was described by Nishiwaki \& Hasegawa (1969) and

61 reviewed by Kimura (2009). Kimura (2009) also described Eubalaena shinshuensis from the latest

62 Miocene of the Gonda Formation, Nagano Prefecture, Japan. A partial skull of an indeterminate

63 species of Eubalaena was described by Bisconti (2002) from the Upper Pliocene of Tuscany,

64 Central Italy. Fragmentary tympanic bullae assigned to Eubalaena spp. were described by Morgan

65 (1994) from the Nashua Formation in Florida (latest Pliocene and earliest Pleistocene) and

66 Boessenecker (2013) from the Purisima Formation in Central California (Late Pliocene). Finally,

67 Field et al. (2017) described a fragmentary skull assigned to Eubalaena sp. from the Tjorres

68 Formation in Island (Early Pliocene).

69 A large-sized balaenid skull from the "Merxemien" of Antwerp, northern Belgium, was described

70 by Plisnier-Ladame \& Quinet (1969) who assigned it to Balaena belgica, a taxon established by

Abel (1941) based on a described and illustrated cervical complex and the mention of other cranial

remains. Bisconti (2003) questioned Abel's taxonomic decision and suggested that the skull should

be assigned to Eubalaena, a proposal supported by later phylogenetic analyses placing 'B.' belgica

as sister-group to E. glacialis (Bisconti, 2005a; Churchill et al., 2012) or as sister-group to the extant Eubalaena species (Marx \& Fordyce 2015). However, a formal re-description of the specimen is currently necessary to make sound taxonomic decisions.

The specimens previously assigned to 'Balaena' belgica consist of: 
80

81

(1969, fig. 1, pls. 1 and 2), and bearings the inventory number of the Royal Belgian Institute of Natural Sciences, Brussels (hereinafter RBINS) RBINS M. 881 (IG 8444);

(2) a partial neurocranium (RBINS M. 879a-f, IG 8652) discovered in 1921 in Oorderen (a part of the Antwerp harbor) during the excavation of the first Kruisschans lock (Figs. 1 and 2), figured by Plisnier-Ladame \& Quinet (1969, pls. 1-2);

(3) a large fragment of right maxilla (RBINS M. 880a-c, IG 8652) also discovered in 1921 in Oorderen during the excavation of the first Kruisschans lock seemingly misidentified as a fragment of mandible by Plisnier-Ladame \& Quinet (1969), but never described or figured;

(4) a large isolated left humerus (RBINS M. 2280) without any locality data, most likely corresponding to the specimen mentioned by Plisnier-Ladame \& Quinet (1969), but never described or figured.

In this paper, the material previously assigned to 'Balaena' belgica Abel, 1941 is newly described and compared with an extended sample of right, bowhead and pygmy right whales to get a comprehensive analysis of anatomy and clear taxonomic assignments. The morphological characters of the skull are then used in a new phylogenetic analysis of living and fossil right and bowhead whales to (1) reveal the timing of the origin of the genus Eubalaena and the divergence time from its closest living relative Balaena mysticetus, and (2) investigate whether the three living right whale populations correspond to three different species confirming or not the results of molecular analyses. Our results will hopefully provide molecular ecologists with useful information for safer reconstructions of past population dynamics of these highly endangered species.

\section{Materials and methods}


AMNH, American Museum of Natural History, New York, USA. IZIKO, IZIKO Natural History

Museum, Cape Town, South Africa. MSNT, Museo di Storia Naturale e del Territorio, Università

106 di Pisa, Calci, Italia. NBC, Naturalis Biodiversity Center, Leiden, The Netherlands. RBINS, Royal

Belgian Institute of Natural Sciences, Brussels, Belgium. Additional abbreviations are provided in the Supplementary Information file.

\section{New species name}

111 The electronic version of this article in Portable Document Format (PDF) will represent a 112 published work according to the International Commission on Zoological Nomenclature (ICZN), 113 and hence the new names contained in the electronic version are effectively published under that 114 Code from the electronic edition alone. This published work and the nomenclatural acts it contains 115 have been registered in ZooBank, the online registration system for the ICZN. The ZooBank 116 LSIDs (Life Science Identifiers) can be resolved and the associated information viewed through 117 any standard web browser by appending the LSID to the prefix http://zoobank.org/. The LSID for 118 this publication is: urn:lsid:zoobank.org:pub:C8D3FE95-303E-4EF4-86DD-1B453E124981. The online version of this work is archived and available from the following digital repositories: PeerJ, PubMed Central and CLOCKSS.

Anatomy

123 Anatomical terms for skull osteology follow Mead and Fordyce (2009); terminology for humerus 124 and cervical vertebrae follows Schaller (1999). 
126

127 Comparative analyses were made with an extended balaenoid sample including specimens from

\section{Comparative analyses} museums MSNT, RBINS, AMNH, NBC and IZIKO (specimens are listed in Bisconti, 2011). In

129 addition, specimens described in literature were used to complement first-hand observations (True, 1904; Omura, 1958; Tomilin, 1967; Tsai \& Fordyce, 2015).

131

132

\section{Body size estimate}

Three methods for body size estimate were followed. First, we used the regression equation provided by Pyenson \& Sponberg (2011) that allows the reconstruction of the total body length based on a measure of the bizygomatic width of the skull. The equation is the following (data in $\mathrm{mm})$ :

(1) $\log ($ total body length $)=0.92(\log ($ bizygomatic width $)-1.64)+2.67$

Pyenson \& Sponberg (2011) used this equation to reconstruct total body lengths of living and fossil cetaceans including mysticetes. Unfortunately, their study did not involve balaenid specimens, therefore we cannot be sure that the equation (1) is well suited to provide an accurate reconstruction of the total body length for Balaenidae. Moreover, results from equation (1) deviated from observed values of intact specimens for amounts ranging from 47 to $37 \%$. Bearing this in mind, we corrected results generated by the equation (1) by reducing our results by 47 and $37 \%$; in so doing, we got two results from equation (1) corresponding to the range of estimates for the total body length of RBINS M. 879a-f.

The second method used the occipital breadth as principal predictor as from the following equation, provided by Evans et al. (2012) (measurements in $\mathrm{mm}$ ):

(2) body mass $=4.924 * 10^{-6}(\text { occipital breadth })^{3.858}$ 
149 The equation (2) showed a high correlation coefficient in mammals $\left(\mathrm{R}^{2}=0.9447\right)$. Once a body

150 mass estimate was obtained, we used equation (3) to obtain an estimate of skeletal length. Equation

151 (3) is the following, as developed by Silva \& Downing (1995):

(3) $\log ($ body mass $)=3.08(\log ($ skeletal length $))-4.84$

153 This equation was extensively used in the reconstructions of body masses and skeletal lengths of

154 living and fossil mammals in previously published papers. Unfortunately, in marine mammals,

155 body mass may change during the life cycle depending on different patterns of activity performed

156 in the year (e.g., foraging, migration, female lactation etc.) thus the body mass estimate provided

157 by equation (3) is to be intended as mean body mass for a whale of a given length (Churchill et al. 158 2014).

159 Unfortunately, none of these equations was tested on balaenid records and it is not known if they 160 are actually able to retrieve correct results in this family. For this reason, we used also the 161 regression equation provided by Bisconti (2002) to predict the total skull length of a balaenid whale 162 based on supraoccipital length. The equation is the following:

164 In this equation, skull length corresponds to condylobasal length. Unfortunately, the correlation

165 coefficient associated to this equation is rather low $\left(\mathrm{R}^{2}=0.5967\right)$ because the regression equation 166 is based on a limited and scattered dataset. Once a condylobasal length is obtained, we inferred the 167 total body length by tripling or quadrupling the condylobasal length. In fact, following Tomilin 168 (1967), the skull length is about 25-to-30\% of the total body length in extant Balaenidae. Presently 169 it is not possible to be sure that this proportion applies to fossil balaenids; however, given that 170 skull and body sizes have important adaptive functions in Balaenidae (Sanderson \& Wassersug, 171 1993), and given that RBINS 879a-f represents an advanced balaenid species (as judged from its 
172 placement in the phylogenetic hypothesis of relationships presented in this paper), there is no

173 reason to propose a fundamentally different skull/body ratio in this specimen.

174

175 Phylogenetic analysis

176 A total of 153 morphological characters were coded for 42 taxa including 3 archaeocetes used as

177 outgroups. The taxonomic sampling adopted here includes representative taxa from all the known

178 mysticete radiations. The family Balaenidae was represented by 11 taxa including Morenocetus

179 parvus; Neobalaenidae was represented by Caperea marginata and Miocaperea pulchra. The

180 Pliocene Eubalaena sp. from Tuscany was included in a phylogenetic analysis for the first time.

181 Characters were coded based on direct examination of specimens and on the literature listed in the

182 Supplementary Information file together with both character list and taxon $\mathrm{x}$ character matrix.

183 Only 2 characters were coded from baleen morphology; all the other characters were coded from

184 the analysis of the skeletal anatomy of mysticetes and archaeocetes. All characters were unordered

185 and unweighted and followed the outgroup polarization criterion.

186 Character choice was made bearing in mind the goal of maximum reduction of homoplasy in the

187 dataset. This goal was achieved by examining the homoplasy level shown by each character states

188 published by Bisconti (2008, 2011), Bisconti et al. (2013), Bisconti \& Bosselaers (2016), Marx

189 (2011) and Boessenecker \& Fordyce (2015). Bisconti et al. (2013) and Bisconti \& Bosselaers

190 (2016) published the consistency index (hereinafter abbreviated as CI) of all the synapomorphies

191 supporting named nodes. Characters with CI $<1$ were considered homoplastic and were excluded

192 from the present dataset. As far as characters from other papers are concerned, it was more difficult

193 to decide whether a character had a homoplastic distribution or not. To get decisions, character

194 states were mapped on published phylogenetic hypotheses and their distributions were assessed by 
195 eye; in the case a character showed scattered distribution across the branches of the Mysticeti tree, 196 then the application of Fitch's (1971) parsimony allowed to decide if the character could be 197 considered homologous or not in those branches.

198 The taxon $\mathrm{x}$ character matrix was treated by TNT (Goloboff et al., 2008) with default parameters

199 for New Technology Search. The synapomorphies were mapped onto the resulting cladogram and 200 were listed through the dedicate commands in TNT. Number of steps added by each character was 201 calculated at relevant nodes to determine whether the character state constituted an ambiguous or 202 unambiguous synapomorphy at the node.

203

204

Stratigraphic consistency index and determination of divergence dates

205 The degree of agreement between the branching pattern and the stratigraphic occurrence of the 206 taxa was assessed by the calculation of the Stratigraphic Consistency Index (hereinafter, SCI) 207 following the method described by Huelsenbeck (1994; see also discussion in Bisconti, 2007). 208 Stratigraphic ages of the taxa were obtained from the Paleobiology Database available at 209 https://paleobiodb.org and mainly compiled by Mark D. Uhen. Adjustments to the ages of the 210 specimens provided by Marx \& Fordyce (2015) were also included where necessary. Stratigraphic 211 ages of the taxa are provided in the Supplementary Information file published in the website of 212 this Journal. The stratigraphic intervals of occurrence of the taxa were used to constrain the 213 divergence dates of the branches included within Balaenoidea in order to get information about 214 the origin of the living right whale and bowhead whale species.

215

\section{Systematic Paleontology}


218 Class MAMMALIA Linnaeus, 1758

219 Order CETACEA Brisson, 1762

220 Clade PELAGICETI Uhen, 2008

221 Clade NEOCETI Fordyce and de Muizon, 2001

222 Suborder MYSTICETI Cope, 1891

223 Infraorder CHAEOMYSTICETI Mitchell, 1989

224 Parvorder BALAENOMORPHA Geisler \& Sanders, 2003

225 Superfamily BALAENOIDEA Flower, 1865

226 Family BALAENIDAE Gray, 1825

227

228 Balaenidae gen. et sp. indet.

229

230

Material. Cervical vertebrae complex RBINS M. 881 (IG 8444). This specimen was first figured 231 and described as the cotype of Balaena belgica by Abel (1941, p. 13; pl. 2, fig. 9), and later 232 commented and re-illustrated by Plisnier-Ladame \& Quinet (1969, fig. 1; pl. 1 and 2, associated to neurocranium RBINS M. 879).

234

235

Locality and horizon information. The specimen was found on March 6, 1914 by G. Hasse in the 236 docks of Antwerp harbor (northern Belgium), more precisely in the "darses I-II" (Fig. 1). Abel 237 (1941) mentions an origin in the "Scaldisien" for this specimen. Now disused, this 238 chronostratigraphic regional unit is roughtly equivalent to the Lillo Formation, a latest early to 239 Late Pliocene lithostratigraphic unit (latest Zanclean to Piacenzian; Laga et al., 2006; De Schepper 240 et al., 2009; see Fig. 2). 
242 Description. The specimen includes a complex formed by fused cervical vertebrae (Fig. 3).

243 Anteriorly, only the ventral portions of the articular facets of the atlas for the occipital condyles of

244 the skull are preserved. The articular surfaces of the facets are highly concave and wide

245 (measurements are provided in Table 1). The articular facets are separated dorsally by a wide

246 concavity that corresponds to the ventral border of the neural canal. Posteriorly, the articular facet

247 of the $7^{\text {th }}$ cervical vertebra for the $1^{\text {st }}$ thoracic vertebra is highly concave and shows a uniformly

248 convex lateral border. Laterally, the ventral apophysis of the atlas protrudes laterally and ventrally

249 and is separated from a small fragment of the ventral apophysis of the axis by a narrow,

250 dorsoventral groove that is slightly oblique in lateral view. The transverse grooves that are

251 sometimes observed in the cervical complexes of Caperea marginata and in balaenid species

252 (Bisconti, 2012) are not seen in this specimen. No additional characters can be described due to

253 the poor preservation of the specimen.

254 Moran et al. (2014) published a study on the ontogenetic fusion of the cervical vertebrae in the

255 extant bowhead whale Balaena mysticetus, observing that total fusion of the vertebral centra in the

256 cervical region occurs between 10 and 20 years after birth. In RBINS M. 881 the fusion appears

257 complete as the grooves observed at the dorsolateral and ventrolateral corners of the cervical

258 complex are not deep and do not allow to separate the centra. It is thus possible that RBINS M.

259881 belonged to an individual of an age included between 10 and 20 years. However, this

260 hypothesis should be tested with comparisons to the fusion pattern of vertebral centra in the

261 cervical region of Eubalaena in a way to get a more accurate estimate of the individual age of this

262 specimen. Unfortunately, such a study is still lacking. 
264 Discussion and taxonomic decision. The specimen represents a complex that presumably includes

265 all the cervical vertebrae of a balaenid whale. The morphology is consistent with that of Balaenidae

266 as in Caperea marginata the ventral apophysis projects much more ventrally and the outline of the

267 posterior articular surface of the $7^{\text {th }}$ cervical vertebra is squared in posterior view. In other

268 mysticetes the cervical vertebrae are not fused; fusion may occasionally occur in the presence of

269 pathological processes, but the involvement of all the cervical vertebrae is extremely rare. It is

270 possible to distinguish the cervical vertebrae of the living species of Eubalaena from the extant

271 Balaena mysticetus based on: (1) shape of the neural apophysis, (2) shape of the neural canal, and

272 (3) size, shape and orientation of the ventral apophysis of the atlas. Unfortunately, the specimen

273 RBINS M. 881 is too poorly preserved to allow a safe identification; in fact, in this specimen the

274 neural apophyses are not preserved, the neural canal is only partly preserved, and the ventral

275 apophyses of the atlas are largely damaged and worn. For this reason, we assign RBINS M.881 to

276 Balaenidae gen. et sp. indet. Consequently, this decision implies that this specimen cannot be

277 designated as the holotype of the species Eubalaena belgica. Therefore, as Abel (1941) designated

RBINS M. 881 as the cotype of 'Balaena belgica and now we assign it to gen. et sp. indet., it

follows that both 'Balaena belgica and its recombination, Eubalaena belgica, are nomina dubia.

280

281

Balaenidae gen. et sp. indet.

282

Material. Fragment of right maxilla RBINS M. 880a-c (IG 8652), mentioned as a fragment of mandible by Plisnier-Ladame \& Quinet (1969, p. 2), but never figured. 
286 Locality and horizon information. The specimen was found at Oorderen during the excavation of

287 the first Kruisschans lock of the Antwerp harbor at a depth of $7.80 \mathrm{~m}$ under the sea level (Fig. 1).

288 The specimen originates from the Lillo Formation ("Scaldisien"), in a level slightly lower than the

289 neurocranium RBINS M. 879 (see below). Its geological age falls in the range 3.7-2.8 Ma (latest

290 Zanclean-Piacenzian; De Schepper et al., 2009; Fig. 2).

291

292

Description. The specimen includes part of the proximal portion of the right maxilla of a balaenid

whale (measurements are provided in Table 1). The maxilla is transversely compressed and bears

an arched and thin lateral border (Fig. 4). Posteriorly, three infraorbital foramina are observed;

ventrally a long groove for the vasculature of the baleen-bearing tissue runs along the whole ventral

surface of the bone. Such a surface is lateromedially and anteroposteriorly concave. It is not clear

if the orientation of this fragment is more similar to Eubalaena and Balaenula (in these taxa the

posterior portion of the maxilla is nearly horizontal in lateral view) or to Balaena mysticetus (in

this species the posterior portion of the maxilla projects dorsally and anteriorly) or to Balaenella

brachyrhynus (in this species the posterior portion of the maxilla distinctly projects anteroventrally).

302

Discussion and taxonomic decision. The specimen RBINS M. 880a-c represents a balaenid

maxilla. In fact it shows a distinctive arch in lateral view, it is transversely compressed, and it displays a longitudinally-developed groove for the vasculature of the baleen-bearing tissue. Unfortunately, it is impossible to reconstruct the original orientation of this fragment in the skull; 
308 maxilla, prevents a safe taxonomic assignment. For this reason, we assign RBINS M. 880a-c to

309 Balaenidae gen. et sp. indet.

310

311 Genus Eubalaena Gray, 1864

312

313

Type species. Eubalaena australis Desmoulins, 1822.

314

Holotype. An unnumbered skeleton housed at the Museum National d'Histoire Naturelle, Paris, 316 France.

Diagnosis of genus. Balaenid cetacean characterized by all the characters diagnostic of the

Eubalaena + Balaenula clade (i.e., rostrum and supraorbital process of the frontal form a right angle in lateral view, nasal and proximal rostrum horizontal in lateral view, orbitotemporal crest well developed on the dorsal surface of the supraorbital process of the frontal, and zygomatic process of the squamosal directed anteriorly so that the posterior wall of the temporal fossa cannot be observed in lateral view) and by the following, exclusively Eubalaena characters: verticallyoriented squamosal, protruding lambdoid and temporal crests, convex and protruding supramastoid crest, dome-bearing supraoccipital, wide and rounded anterior process of supraoccipital, and pars cochlearis of petrosal protruded cranially.

Discussion. Bisconti (2003) provided the last diagnosis of Eubalaena published up to the present work; diagnostic characters included: gigantic body size (maximum body length approaching 22 m), rostrum and supraorbital process of frontal form a right angle, nasal and proximal rostrum 
331 horizontal, ascending temporal crest well developed on the dorsal surface of the supraorbital

332 process of the frontal, vertically-developed squamosal, zygomatic process of the squamosal

333 directed anteriorly so that the posterior wall of the temporal fossa cannot be observed in lateral

334 view, protruding lambdoidal and temporal crests, convex and protruding lateral squamosal crest,

335 exoccipital squared in lateral view, dome-bearing supraoccipital shield with sagittal crests, wide

336 anterior process of supraoccipital, pars cochlearis cranially-protruding, and superior process of

337 petrosal cranially-protruding. Bisconti's (2003) diagnosis is certainly useful to separate extant

338 Eubalaena from other living balaenids but it may be of limited help when trying to separate fossil

339 Eubalaena species from other living and fossil balaenids. In particular, the above diagnosis

340 includes characters that are shared with the extinct Balaenula lineage: rostrum and supraorbital

341 process form a right angle, nasal and proximal rostrum horizontal, ascending temporal crest

342 (orbitotemporal crest sensu Mead \& Fordyce, 2009) well developed on the dorsal surface of the

343 supraorbital process of the frontal, and exoccipital squared in lateral view. All these characters can

344 be observed also in Balaenula astensis or in Balaenula balaenopsis. A more detailed diagnosis of

345 Eubalaena allowing to separate this genus from all the other living and extinct balaenid taxa

346 includes the characters listed in the Emended diagnosis of genus provided above.

347

348 Eubalaena sp. indet.

349

350 Material. Left humerus RBINS M. 2280, mentioned by Plisnier-Ladame \& Quinet (1969, p. 2), 351 but never figured. 
353 Locality and horizon information. Antwerp area. There is no precise locality data available for this

354 specimen. A stratigraphic assessment is currently impossible.

355

356 Description. This well-preserved, robust left humerus shows a highly rounded proximal articular

357 head that is anteriorly bounded by a protruding deltoid tuberosity; the latter is triangular in lateral

358 view (measurements are provided in Table 1). The diaphysis shows straight anterior and posterior

359 borders (Fig. 5); the posterior border is shorter than the anterior border, as it terminates more

360 proximally due to the development of the articular facet for the olecranon process of the ulna. Such

361 a facet protrudes posteriorly and occupies part of the posterior border of the humerus. The

362 anteroventral corner of the humerus protrudes anteriorly forming a kind of triangular tuberculum.

363 The articular facets for radius and ulna are separated by a transverse protrusion that is triangular

364 in lateral view.

365

366

Discussion and taxonomic decision. The morphology of the articular head of the humerus RBINS

M. 2280 is consistent with both Eubalaena and Balaena. In Eubalaena glacialis the external

border of the lateral surface of the articular head shows a posterior concavity that is not seen in preventing a clear understanding of its morphology. More distally, the articular facet for the

372 it is largely reduced. Benke (1993) showed that the posterior border of the diaphysis in Balaena

373 mysticetus is uniformly concave and short and that the deltoid tuberosity is less protruding than in

374 Eubalaena glacialis. In the latter, the posterior border of the diaphysis is more elongated

375 (resembling that of RBINS M. 2280) and the deltoid tuberosity is triangular and protruding. In the 
376 humerus RBINS M.2280 the deltoid tuberosity is triangular and protruding as in E. glacialis.

377 However, the posterior border of the diaphysis of RBINS M. 2280 is straighter than that observed 378 in E. glacialis.

379 Comparative analysis shows, thus, that the humerus RBINS M. 2280 is closer to Eubalaena than

380

381

382

383

384

385

386

387

388

389

390

391

392

393

394

395

396

397

to Balaena, as it shares with E. glacialis the presence of (1) well-developed and protruding articular facet for the olecranon process, (2) triangular and protruding deltoid tuberosity and, (3) comparatively long posterior border of the diaphysis. These shared characters allow inclusion of RBINS M. 2280 within Eubalaena. However, the different shape of the posterior border of the diaphysis and the lack of information about the shape of the lateral outline of the articular head do not allow inclusion of this specimen within E. glacialis or other extant Eubalaena species. RBINS M. 2280 is thus assigned to Eubalaena sp. indet.

When compared to the extant Eubalaena species, this humerus is particularly long suggesting that it belonged to a large individual. The total proximodistal length of RBINS M. 2280 is $683 \mathrm{~mm}$, which is greater than the maximum humeral lengths published by Benke (1993) for Balaena mysticetus (i.e., $605 \mathrm{~mm})$, Eubalaena glacialis $(555 \mathrm{~mm})$, and E. australis $(619 \mathrm{~mm})$, and by Omura (1958) for E. japonica $(556 \mathrm{~mm})$. Based on this comparison, we suggest that the humerus RBINS M. 2280 belonged to an individual that was longer than $16.5 \mathrm{~m}$. This is the first report of a gigantic right whale in the fossil record of the North Sea.

Eubalaena ianitrix sp. nov. LSID: urn:Isid:zoobank.org:act:F17C4DCA-FF1B-4EA4-9E6B6C1EED448745 
398

399

400

401

402

403

404

405

406

407

408

409

410

411

412

413

414

415

416

417

419

420

418 Type horizon. Based on data associated to the neurocranium RBINS M. 879a-f, Misonne (1958)

Derivation of name. The specific name ianitrix derives from Ianus, the Roman God who was the guardian of passages, gates and doors. This name is related to the discovery of the holotype in the locks (or entrances) of the Antwerp harbor.

Holotype. The holotype is housed at the Royal Belgian Institute of Natural Sciences, Brussels, Belgium, and bears the inventory number M. 879a-f, Reg. 4019, I.G. 8652 (all the numbers refer to the same individual). It includes a partial skull (M. 879a), right squamosal and exoccipital (M. 879b), left squamosal and exoccipital (M. 879c), fragment of a maxilla (M. 879d), fragment of the right supraorbital process of the frontal (M. 879e), fragment of the left supraorbital process of the frontal (M. 879f). It was first figured and described as Balaena belgica by Plisnier-Ladame \& Quinet (1969, p. 2; pl. 1-2, associated to cervical complex RBINS M. 881).

Type locality. The neurocranium RBINS M. 879a-f was discovered in Oorderen (Fig. 1) during the excavation of the first Kruisschans lock ('première écluse du Kruisschans', now named Van Cauwelaertsluis) of the Antwerp harbor (Plisnier-Ladame \& Quinet, 1969). Geographic coordinates: $51^{\circ} 16^{\prime} 32^{\prime \prime} \mathrm{N}-04^{\circ} 19^{\prime} 51^{\prime \prime} \mathrm{E}$. As mentioned above, the maxilla RBINS M. 880a-c was found at the same site. However, based on labels associated to specimens, the neurocranium was found at a depth of $3.70 \mathrm{~m}$ under the sea level, whereas the maxilla was found at a depth of 7.80 $\mathrm{m}$ under the sea level, therefore most likely not representing the same individual. indicated an origin in the Kruisschans Sands ('Sables du Kruisschans'; Fig. 2) in the 'zone à Cardium', and a Merksemian ('Merxemien') stage, a stage assignation later confirmed by Plisnier- 
421 Ladame \& Quinet (1969). Now disused, this regional stage was first introduced by Heinzelin

422 (1955a), including the Kruisschans Sands and Merksem Sands, together with an underlying gravel

423 layer (Laga \& Louwye, 2006). Both the Kruisschans Sands Member and Merksem Sands Member

424 are now part of the Lillo Formation, constituting its two youngest members (Vandenberghe et al., 425 1998; Laga et al., 2006).

426 In published sections of the Pliocene and Quaternary layers at the Kruisschans locks (including 427 sections in a new lock parallel to the ancient lock, 'Ecluse Baudouin'), a clayey sand layer 428 containing a high concentration of shells of the bivalve Laevicardium (first named Cardium) 429 parkinsoni and isolated cetacean bone fragments is reported at a depth of 5.5-7 m (Heinzelin, 1952, 430 1955b). This shell layer is located about $1 \mathrm{~m}$ above the base of the Kruisschans Sands. It is 431 therefore tempting to propose that the 'zone à Cardium' mentioned by Misonne (1958) for the 432 horizon of the skull RBINS M. 879a-f corresponds to this part of the Kruisschans Sands.

433 Dinoflagellate cysts from a section $4 \mathrm{~km}$ north to the Kruisschans locks give a Piacenzian (Late 434 Pliocene) age to both the Kruisschans Sands Member and the overlying Merksem Sands Member, 435 older than 2.6 Ma (as confirmed by pollens) and most likely somewhat younger than 3.7 Ma (age 436 of the base of the Lillo Formation), whereas sequence stratigraphy narrows even more their 437 temporal range to 3.2 to $2.8 \mathrm{Ma}$ (De Schepper et al., 2009). RBINS M. 879a-f is therefore proposed 438 to date from that Piacenzian interval.

439 The record of fossil marine mammals in the Kruisschans Sands Member is relatively poor; only 440 the odobenid Alachtherium antwerpiensis and the stem phocoenid Septemtriocetus bosselaersi are 441 known to originate from that unit (Hasse, 1909; Lambert, 2008). 
443 Diagnosis. Eubalaena ianitrix differs from E. shinshuensis in showing a distinctive anteroventral

444 corner in the parietal-frontal suture and in having an anterodorsally protruded squamosal-parietal

445 suture; it differs from the Eubalaena sp. from the early Late Pliocene of Tuscany (included in our

446 diagnosis considering that in our phylogenetic analysis it represents a true right whale species

447 needing a new species name) in having an anteriodorsally protruded squamosal-parietal suture; it

448 differs from E. japonica in having the pterygoid exposed in the temporal fossa, in having 449 posteromedially directed anterior borders of the palatine and in having anteriorly directed posterior 450 borders of the palatine; it differs from E. australis in having a less protruding anteroventral corner 451 in the parietal-frontal suture, in having an anterodorsally protruded squamosal-parietal suture, in

452 having the pterygoid exposed in the temporal fossa and in having anteriorly directed posterior 453 border of the palatine; it differs from E. glacialis in having a crest located at the squamosal454 parietal-supraoccipital suture and in having anteriorly directed posterior border of the palatine.

455 Eubalaena ianitrix does not possess any autapomorphy and may be distinguished from other 456 Eubaena species by the following combination of characters: bilateral bulge on supraoccipital with 457 presence of sagittal crest, alisphenoid exposed in the temporal fossa, and alisphenoid dorsally 458 bordered by a squamosal projection that prevents it to make contact with parietal.

Comparative anatomy of the skull of Eubalaena ianitrix

461

462 The holotype specimen consists of a moderately well preserved partial skull. The skull is massive 463 and heavy and lacks part of the supraoccipital borders due to post-mortem erosion. It is subdivided 464 into six fragments that can be put together due to clear break surfaces. Measurements are provided 465 in Table 2. 
467 Rostrum. Only a fragment of the right maxilla is preserved showing the typical transverse 468 compression present in Balaenidae.

469

470

Frontal. Due to the erosion of the anterior-most border of the supraoccipital, it is possible to 471 observe a tiny portion of the interorbital region of the frontal in dorsal view (Figs 6). Prior to the 472 erosion of the supraoccipital, that portion was superimposed by the anterior portion of the 473 supraoccipital and was not visible. Judging from what is preserved, the interorbital region of the 474 frontal was less bent than the supraoccipital suggesting that, in lateral view, the posterior portion 475 of the rostrum was nearly flat as seen in Eubalaena glacialis. The transverse diameter of the 476 interorbital region (measured along the inferred position of the nasofrontal suture) is $c .240 \mathrm{~mm}$.

477 The supraorbital processes of the frontal are detached from the skull probably because post478 mortem damage. The supraorbital process of the frontal is anteroposteriorly narrow and bears an 479 evident but rounded orbitotemporal crest developed from the postorbital process to its 480 anteromedial border (Figs 6, 7 and 8). The orbitotemporal crest is sharper proximally and becomes 481 lower approaching the orbital rim. The right supraorbital process of the frontal is $650 \mathrm{~mm}$ in length 482 up to the center of the orbit. The left supraorbital process of the frontal is $712 \mathrm{~mm}$ in length. A 483 long groove for articulation with the maxilla is located at the anteromedial corner of the left 484 supraorbital process of the frontal (Fig. 9).

485 The optic canal is deep proximally (depth is $c .45 \mathrm{~mm}$ ) and shallow distally (depth is $c .35 \mathrm{~mm}$ ). 486 Proximally, the right optic canal is bordered by anterior and posterior crests whose distance is 50 487 mm proximally and c. $100 \mathrm{~mm}$ distally (Fig. 10). The anteroposterior diameter of the left optic 
488 canal is $30 \mathrm{~mm}$ proximally at a distance of $400 \mathrm{~mm}$ from the orbital rim and $70 \mathrm{~mm}$ a few $\mathrm{mm}$

489 from the orbital rim.

490 Approaching the orbit, the dorsal surface of the supraorbital process of the frontal flattens. The 491 right orbit is $170 \mathrm{~mm}$ in length (from the center of the postorbital process of the frontal to the 492 center of the antorbital process of the frontal) and $51 \mathrm{~mm}$ in height (measured from the center of 493 the orbital rim to an imaginary line joining antorbital and postorbital processes of the frontal). On 494 the right side, antorbital and postorbital processes are similar in size but on the left side, the 495 postorbital process is more robust than the antorbital process (Figs 7 and 8). The longitudinal axis 496 of the supraorbital process of the frontal is perpendicular to the imaginary line joining antorbital 497 and postorbital processes. This suggests that, in the living animal, the supraorbital process of the 498 frontal formed an approximately right angle with the lateral process of the maxilla and, thus, 499 resembling the condition observed in the right whale of the genus Eubalaena and the fossil 500 Balaenula.

501 The frontal of Eubalaena ianitrix shares the following characters with the living Eubalaena and 502 Balaenula: presence of an evident orbitotemporal crest developed from the postorbital process to 503 the anteromedial corner of the supraorbital process of the frontal, lack of dorsoventral compression 504 along most of the length of the supraorbital process of the frontal (as seen in Morenocetus parvus, 505 Balaena mysticetus and Balaenella brachyrhynus), presence of a right angle between supraorbital 506 process of the frontal and the lateral process of the maxilla in lateral view, interorbital region of 507 the frontal clearly angled with respect to the dorsoventral inclination of the supraoccipital. The 508 articular groove for the maxilla combined with the short anteroposterior diameter of the proximal 509 portion of the supraorbital process suggests that the ascending process of the maxilla was short 510 and wide like that typically observed in the other Balaenoidea where this structure has been 
511 described (Bisconti, 2012 and literature therein). The short exposure of the interorbital region of

512 the frontal on the dorsal surface of the skull and the exclusion of the parietal from exposure at

513 cranial vertex are typical characters of living and fossil Balaenoidea.

514

515 Parietal. The parietal is evident on the lateral sides of the skull and at the cranial vertex due to the

516 erosion of the anterior-most border of the supraoccipital (Fig. 6). Originally, the parietal was

517 covered by the anterior border of the supraoccipital forming the nuchal crest. The frontal border

518 of the parietal is superimposed on the interorbital region of the frontal obliterating it in dorsal view.

519 More laterally, the frontal border descends ventrally and posteriorly and borders the posterodorsal

520 portion of the supraorbital process of the frontal and forming an anteriorly convex coronal suture.

521 Posteriorly to the supraorbital process of the frontal, the coronal suture forms a curve with anterior 522 concavity and projects ventrally and posteriorly (Figs 7, 8).

523 The shape of the coronal suture is different in different balaenoid lineages. In the skull of Caperea 524 marginata as seen in lateral view, the frontal border of the parietal gently descends from an 525 anterodorsal point to a point located posterventrally in a straight-to-slightly convex line located 526 dorsally to the supraorbital process of the frontal. This shape of the frontal border of the parietal 527 is shared also with Balaena mysticetes, B. montalionis, B. ricei and Balaenella brachyrhynus. In 528 the fossil Miocaperea pulchra, the right parietal shows a slightly different condition; in this species 529 a distinctive anteroventral corner is located along the frontal border of the parietal (Bisconti, 2012).

530 The anteroventral corner is present also in the species belonging to Balaenula and Eubalaena and 531 in Eubalaena ianitrix (Figs 7, 8). In Eubalaena australis, posterior to the anteroventral corner, the

532 frontal border shows a strong ventral concavity and a rounded shape making it distinct from the 533 parietal of all the other balaenoid species. 
534 The supraoccipital border of the parietal protrudes laterally and, together with the lateral border of

535 the supraoccipital, forms the temporal crest. The temporal crest protrudes laterally and forms a sort

536 of short roof of the temporal fossa in such a way that it prevents the medial wall of the temporal

537 fossa (formed by the external surface of the parietal) from being observed in dorsal view. The

538 external surface of the parietal is widely concave. Along the anteroposterior axis of the skull, the

539 parietal appears short and high. The dorsal portion of the squamous border is anteroposteriorly

540 elongated and bears a weak crest; the ventral portion of the squamous border forms a highly

541 interdigitated suture with the squamosal and projects ventrally.

542 Among Balaenidae, a crest along the squamous border has been detected as a synapomorphy of

543 Balaena and Balaenella by Bisconti (2005a) and Churchill et al. (2012) as it is absent from

544 Balaenula and Eubalaena. It is not clear whether this crest is present in Morenocetus and

545 Peripolocetus. The shape of the frontal border of the parietal differs from that observed in Balaena

546 and Balaenella as it shows an undulating development; in Balaena and Balaenella the frontal

547 border of the parietal proceeds posteroventrally as a straight line. A highly interdigitated ventral

548 portion of the squamous border of the parietal is also observed in a subadult individual of $E$.

549 australis (specimen NBC RGM 24757).

550 The squamous border of the parietal has distinctive characters in different balaenoid lineages. In

551 Caperea marginata, the dorsal portion of the squamous border projects posteriorly to meet the

552 supraoccipital (Bisconti, 2012). This character is also observed in Balaena mysticetus adult NBC

553 RGM 373 and foetal NBC RGM 31116; the character was also illustrated by Cuvier, 1823; see

554 Bisconti, 2003 for an image), Eubalaena australis adult IZIKO 2284, subadult NBC RGM 24757

555 and foetal IZIKO ZM 38950) and in the Pliocene Eubalaena sp. from Tuscany (Bisconti, 2002).

556 In Miocaperea pulchra and Balaenella brachyrhynus the dorsal portion of the squamous border is 
557 nearly vertical. In Eubalaena glacialis, E. japonica, Balaenula astensis and Eubalaena ianitrix the

558 dorsal portion of the squamous border projects anteriorly forming a finger-like structure that is

559 deeply wedged between the parietal and the supraoccipital.

560

561 Supraoccipital. The supraoccipital is strongly built and represents the largest bone of this skull

562 (Fig. 6). Parts of the anterior and lateral borders are missing due to post-mortem erosion of the 563 skull and to damage done during the collection and preparation of the skull. The supraoccipital is

564 wide and, as preserved, shows a convex lateral border and a widely rounded anterior border. The 565 anteroposterior length (from the anterior border to the inferred position of the dorsal edge of the 566 foramen magnum) is c. $531 \mathrm{~mm}$; the transverse diameter is $c .350 \mathrm{~mm}$ anteriorly and c. $590 \mathrm{~mm}$ 567 at mid-length. The external occipital protuberance, located on the anterior surface of the 568 supraoccipital, is dorsally convex and forms a wide dome bordered by bilateral fossae located near 569 the lateral borders of the supraoccipital. The dome consists of relief posteriorly subdivided by the 570 interposition of a triangular, parasagittal fossa. There is a low sagittal crest located posteriorly to

571 the dome. In lateral view, the dome is clearly visible as it protrudes dorsally and is not obliterated

572 to view by the temporal crests. Before the post-mortem erosion of the skull, the supraoccipital

573 formed a dorsal roof to the temporal fossa preventing the parietal from being observed in dorsal 574 view.

575 In the genus Eubalaena, the supraoccipital is anteriorly wide and rounded and displays an external 576 occipital protuberance that is dome-shaped. These characteristics of the supraoccipital are 577 observed in all the living Eubalaena species, in the fossil E. shinshuensis and in the Eubalaena sp. 578 described by Bisconti (2002) from the Pliocene of Tuscany. Subtle differences in the characters of 579 the dome could be used for differentiating the species of Eubalaena but it is not completely clear 
580 whether the differences are due to individual variation or have taxonomic value. Bisconti (2002)

581 described a sagittal crest on the external occipital protuberance and a series of five parasagittal

582 crests posterior to it in a Pliocene Eubalaena sp. The five parasagittal crests are not observed in

583 other Eubalaena species. A single sagittal crest is present in Eubalaena australis (NBC RGM

584 24757), Eubalaena glacialis (AMNH 42752, MSNT 264) E. japonica (Omura, 1958) and

585 Eubalaena ianitrix.

586 The external supraoccipital protuberance is formed by a bilateral bulge in Eubalaena australis

587 (NBC 24757), E. glacialis (AMNH 42752), Eubalaena sp. (Bisconti, 2002), and E. ianitrix, and

588 by a single axial bulge in E. japonica and E. shinshuensis (Kimura, 2009). The external

589 supraoccipital protuberance is a single bulge also in Balaena mysticetus, Balaena montalionis,

590 Balaena ricei and Balaenella brachyrhynus but in these species the anterior portion of the 591 supraoccipital is transversely constricted while in the species belonging to Morenocetus, 592 Balaenula and Eubalaena the anterior portion of the supraoccipital is transversely wide.

593 Observations on skulls belonging to living species suggest that the lateral borders of the 594 supraoccipital potentially undergo morphological change during ontogeny. In Eubalaena 595 australis, the lateral border of the supraoccipital is externally convex in fetal and subadult 596 individuals (ISAM ZM 38950, NBC RGM 24757). Omura (1958) observed that in adult

597 individuals of Eubalaena glacialis the lateral border of the supraoccipital is more concave that in 598 E. japonica. However, in the images provided by True (1904), an adult individual of Eubalaena 599 glacialis has a continuously convex lateral border of the supraoccipital. It is possible that Omura's 600 (1958) observation was related to differences in the point of view from which the skulls were 601 observed (Yamada et al. 2006).

602 
603 Vertex. Based on Mead \& Fordyce (2009, and literature therein) terminology, the vertex is the

604 highest portion of the skull. In mysticetes it is formed by a mosaic of bones including 605 supraoccipital, parietal, frontal and some posteromedial elements of the rostrum nasal and the 606 ascending process of the premaxilla and of the maxilla). In E. ianitrix, the supraoccipital overlaps 607 onto the parietal and prevents it from being observed in dorsal view (Fig. 6). The parietal is 608 superimposed onto the interorbital region of the frontal that is, thus, scarcely visible in dorsal view. 609 The only portion of the interorbital region of the frontal that can be observed is that that is 610 immediately posterior to the nasofrontal suture. Judging from the articular groove present on the 611 anteromedial surface of the supraorbital process of the frontal, the ascending process of the maxilla

612 had a limited posterior extension resembling other living and fossil Balaenoidea.

613 The supraoccipital superimposition on the parietal and the parietal superimposition on the 614 interorbital region of the frontal are synapomorphies of Balaenidae and Neobalaenidae and are not 615 shared with other mysticete taxa (Bisconti, 2012 and literature therein). The lack of parietal 616 exposure at the cranial vertex is another exclusive feature of Balaenidae and Neobalaenidae and is 617 observed in all the living and fossil taxa belonging to these groups (Churchill et al., 2012; Bisconti, 618 2003).

619

620 Exoccipital. The lateral portion of the exoccipital is a wide and flat surface with external border 621 squared (Fig. 11). Only the left paroccipital process is preserved and appears strong and rugose in 622 ventral view. A squared external border of the exoccipital is observed in Eubalaena japonica and, 623 at a lesser extent, in Eubalaena australis. In E. glacialis the external border has a rounder shape 624 than in those species. In Balaena mysticetus and B. montalionis the external border of the 625 exoccipital appears anterolaterally round with a distinctive lateroventral corner that is observed 
626 also in E. glacialis but that seems absent in E. japonica (Omura, 1958). In lateral view, the 627 exoccipital has a squared shape in E. glacialis, E. australis, E. japonica and the species belonging 628 to Balaenula but it is not clear whether a squared shape is also present in Eubalaena ianitrix.

629 The occipital condyle is wide, reniform and its surface for articulation with the atlas is nearly flat 630 along both the dorsoventral and the lateromedial axes. The main axis of the occipital condyle is 631 oriented from a posteroventral point to an anterolateral point. There is a wide intercondyloid fossa 632 located ventrally between the condyles. The condyles are not in contact each other ventrally or 633 dorsally. The maximum anteroposterior diameter of the occipital condyle is 190 on the right side 634 and 170 on the left side; the maximum lateromedial diameter of the occipital condyle is 101 on the 635 right side and 107 on the right side. The condyles surround a wide foramen magnum whose dorsal 636 border is not preserved. The maximum tansverse diameter of the foramen magnum is $145 \mathrm{~mm}$ and 637 its dorsoventral diameter is inferred to be $c .140 \mathrm{~mm}$ based on a nearly circular outline with a slight 638 dorsoventral compression as seen in other balaenid species. The distance between the external 639 borders of the occipital condyles is c. $350 \mathrm{~mm}$.

640

641 Squamosal. Right and left squamosals are partly broken; breakage lines are straight enough to 642 allow an easy reconstruction of this part of the skull by putting the broken portions of the 643 squamosals in place through right connections (Figs 7, 8).

644 The parietal margin of the squamosal forms the squamosal-parietal suture. Dorsally, this suture 645 projects anteriorly making it possible for the squamosal to be deeply inserted between the 646 supraoccipital and the parietal. More ventrally, the squamosal-parietal suture is highly 647 interdigitated. 
648 The squamosal plate is dorsoventrally and anteroposteriorly concave and, in lateral view, it is 649 hidden by the anterior and ventral development of an anteriorly convex supramastoid crest. The 650 supramastoid crest is protruding anterolaterally and shows a widely rounded anterior shape. The 651 supramastoid crest is separated from the zygomatic process of the squamosal by a wide anterior 652 concavity. The zygomatic process of the squamosal is short and stocky; its main axis projects 653 laterally and ventrally in dorsal view.

654 The squamosal has a clear dorsoventral development as typically observed in Balaenidae. Its 655 dorsoventral diameter is $550 \mathrm{~mm}$ on the external surface (from the exoccipital-squamosal suture 656 to the anterior end of the zygomatic process of the squamosal) of the right squamosal. The glenoid 657 fossa of the squamosal is largely eroded; what remains suggests that it was flat or scarcely concave 658 as seen in other typical balaenid whales. The glenoid fossa of the right squamosal is $470 \mathrm{~mm}$ in 659 anteroposterior length.

660 Posterodorsally, the site for the articulation with the posterior process of the petrotympanic is 661 developed ventrally to the exoccipital-squamosal suture and is ventrally bordered by a crest that 662 separates it from the external acoustic meatus. Both this site and the external acoustic meatus are 663 represented by transverse and tube-like concavities developed along the dorsal and posterior 664 portion of the squamosal. The posterior border of the foramen ovale is made of the squamosal and 665 the pterygoid.

666 The squamosal of Eubalaena ianitrix shows the following typical balaenid characters: dorsoventral 667 elongation, reduction of the zygomatic process of the squamosal, scarcely concave glenoid fossa 668 of the squamosal, widely rounded supramastoid crest in lateral view. In Balaenella and in the 669 species of Balaena the squamosal is also posteroventrally oriented (Bisconti, 2000) but this 670 character is not observed in E. ianitrix. Rather, the squamosal of E. ianitrix appears more vertical 
671 resembling Morenocetus, Balaenula and the living species of Eubalaena. In Balaenella 672 brachyrhynus, Balaena mysticetus, B. ricei, and B. montalionis the zygomatic process of the 673 squamosal projects more laterally allowing the view of the posterior wall of the temporal fossa 674 formed by the squamosal plate. In Eubalaena, Balaenula and E. ianitrix this is not the case as the 675 zygomatic process of the squamosal projects anteriorly and prevents the posterior wall of the 676 temporal fossa from being observed in lateral view.

677

678 Alisphenoid. The alisphenoid is exposed in the temporal fossa. It has a triangular shape. It is 679 bordered anteriorly by the supraorbital process of the maxilla, ventrally by the palatine, and 680 dorsally and posteriorly by the squamosal.

681 The alisphenoid is exposed in the temporal fossa in Eubalaena glacialis and E. japonica but it is 682 not clear whether such an exposure occurs also in E. australis. In fetal specimen (IZIKO ZM 683 38950) the alisphenoid is observed in the temporal fossa but in subadult individual (NBC RGM 684 24757) the alisphenoid is only visible in ventral view and does not appear in the temporal fossa as 685 the ventral border of the squamosal superimposes onto it. In Balaena mysticetus, B. brachyrhynus, 686 and in the genus Balaenula the alisphenoid is inferred to be exposed in the temporal fossa based 687 on the articular pattern of squamosal and parietal. The alisphenoid was originally bordered by the 688 squamosal dorsally and posteriorly and by the parietal dorsally and anteriorly, by the palatine 689 ventrally.

690

691 Temporal fossa. The temporal fossa of E. ianitrix is dorsally overhung by the lateral projection of 692 the temporal crest formed by the lateral border of the supraoccipital and the dorsal border of the 693 parietal (Fig. 6). The lateral extension of the temporal crest is difficult to assess because the lateral 
694 edge of the supraoccipital and the dorsal border of the parietal are damaged. The medial wall of

695 the temporal fossa is formed by parietal, squamosal and alisphenoid. The alisphenoid is not in

696 contact with the parietal; the parietal-squamosal suture is highly interdigitated ventrally but,

697 dorsally, the squamosal forms a digit-like anterior protrusion that is deeply inserted between the

698 supraoccipital and the parietal. The medial wall of the temporal fossa is concave both

699 dorsoventrally and anteroposteriorly. The posterior wall of the temporal fossa is formed by the

700 squamosal and shows an anterior concavity. Lateral to the posterior wall of the temporal fossa, the

701 supramastoid crest protrudes anteriorly and forms the lateral border of the squamosal fossa.

702 The general features of the temporal fossa of E. ianitrix are also observed in Eubalaena glacialis

703 and E. japonica. Eubalaena australis differs in the lack of exposure of the alisphenoid in the

704 temporal fossa at adulthood. In the Pliocene Eubalaena sp. from Tuscany (Bisconti, 2002) and

705 Eubalaena shinshuensis (Kimura, 2009) the digit-like projection of the anterodorsal portion of the

706 squamosal is absent. In Balaenula the posterior apex of the lambdoid crest is located much more

707 anteriorly than in any species belonging to Eubalaena, Balaena and Balaenella and this makes its

708 temporal fossa anteroposteriorly smaller; moreover, in Balaenula astensis the posterior wall of the

709 temporal fossa is mainly flat along the dorsoventral axis (Bisconti, 2000, 2003).

710

711 Palatine. The palatine is almost rectangular in ventral view (Fig. 10). It is an elongated bone that

712 is anteriorly in contact with the maxilla and posteriorly with the pterygoid. As typically observed

713 in Balaenidae, the palatine is ventrally superimposed on the ventral lamina of the pterygoid that

714 appears, in ventral view, as a small stripe of bone close to the posterior limit of the skull. The

715 ventral surface of the palatine is almost flat. The longitudinal axis of the palatine diverges from

716 the anteroposterior axis of the skull posteriorly as the posterior ends of the palatines are not in 
717 contact posteriorly. The lateral lamina of the palatine ascends and contacts the squamosal, the

718 alisphenoid and the frontal.

719 The relationships of the palatine observed in E. ianitrix are not different from those that can be

720 observed or inferred in other living and fossil Balaenidae for which information about this bone is

721 available.

722

723 Pterygoid. Following Churchill et al. (2012), Bisconti (2000, 2005a) and Fraser \& Purves (1960),

724 in Balaenidae the pterygoid appears as a small stripe of bone in ventral view. This stripe of bone

725 represents the lateral lamina of the pterygoid that is transversely elongated and approaches the

726 posterior-most border of the skull in lateral view. The pterygoid is dorsally, anteriorly and

727 posteriorly bordered by the squamosal and anteroventrally by the palatine. The posterior border of

728 the pterygoid and the anterior border of the falciform process of the squamosal contribute to delimit

729 the shape of the foramen ovale (Fig. 10).

730 Apart from Caperea marginata, in which the foramen ovale is within the pterygoid, the foramen

731 ovale of other balaenoids is located between the squamosal and the pterygoid. In the living species

732 the foramen ovale extends into a tube formed almost entirely by the squamosal (= infundibulum

733 of Fraser and Purves, 1960). This condition is not observed in E. ianitrix where the foramen ovale

734 has an elliptical shape.

735

736 Body size estimate

737

738 Two of the chosen methods converge towards a total body length or c.6-8 m. The application of

739 equation (1) based on a bizygomatic width of $1660 \mathrm{~mm}$ (Table 2) retrieved a total body length of 
740 c. $13 \mathrm{~m}$; this result is to be corrected by reducing it of $37-$ to- $47 \%$. After the correction, the resulting

741 values are respectively c. $8 \mathrm{~m}$ and c. $7 \mathrm{~m}$.

742 The application of the regression equation (4) based on a supraoccipital length of $560 \mathrm{~mm}$ (Table

743 2) found a condylobasal length of $c .1 .6 \mathrm{~m}$. After having tripled and quadrupled this length, the

744 total body length was estimated between 4.74 and $6.37 \mathrm{~m}$.

745 The application of the equation (2) based on an occipital breadth of $353 \mathrm{~mm}$ retrieved a body mass

746 of c. 33 t. This value is consistent with weight values obtained by Omura et al. (1958) for the North

747 Pacific right whale (E. japonica). We used this body mass estimate in the equation (3) and found

748 a total body length of $c .11 \mathrm{~m}$, which is closer to the result obtained from the equation (1) before

749 the correction. It is not clear whether the results of the equation (3) need to be corrected but,

750 following the suggestions of Pyenson \& Sponberg (2011), we hypothesize that a correction would

751 be necessary that should be around 40\%. If we apply such a correction to the value obtained by

752 the equation (3), we find a total body length of c. $6.6 \mathrm{~m}$ that is very close to the higher results of 753 the equations (1) and (4). If we accept a total body length between 6 and $7 \mathrm{~m}$ then we need to apply

754 a roughly similar correction to the estimated body weight. If we reduce the estimated body weight 755 of $40 \%$ then we obtain an estimated body weight of $19.8 \mathrm{t}$.

756 We therefore estimate the total body length of the holotype specimen of Eubalaena ianitrix 757 between 5 and $7 \mathrm{~m}$, with a body mass of c. $20 \mathrm{t}$.

758

759 Phylogeny

760

761

Overview 
762 The phylogenetic analysis resulted in the single most parsimonious cladogram shown in Fig. 12 .

763 Tree statistics are provided in the corresponding caption. Our results confirm the monophyly of

764 Mysticeti, Chaeomysticeti and Balaenomorpha. The sister-group of Balaenomorpha is the

765 monophyletic Eomysticetidae (here represented by Eomysticetus whitmorei, Tokaraia kauaeroa

766 and Yamatocetus canaliculatus). Balaenomorpha is then subdivided into two sister-groups:

767 Balaenoidea and Thalassotherii (including Balaenopteridae, Eschrichtiidae, Cetotheriidae and

768 basal thalassotherian taxa including Cophocetus, Aglaocetus, Parietobalaena, Isanacetus,

769 Uranocetus, Pelocetus and Diorocetus). As such, the present results confirm the monophyly of

770 Balaenopteroidea (including Balaenopteridae and Eschrichtiidae) and Cetotheriidae (here

771 including Mixocetus, Herentalia, Piscobalaena, Herpetocetus and Tranatocetus). Tranatocetus

772 argillarius is nested here among Cetotheriidae. Although this may be due to our limited sample of

773 Cetotheriidae and related taxa, we are unable to support the monophyly of Tranatocetidae (as

774 proposed by Gol'din \& Steeman, 2015), considering that T. argillarius (the only nominal

775 Tranatocetidae taxon included in our analysis) falls within Cetotheriidae.

776 Most surprising are the position of Morenocetus parvus (that will be discussed in the next

777 paragraph) and the sister-group relationships within Thalassotherii. Among Thalassotherii, four

778 monophyletic groups of family-level rank are recognized: Balaenopteridae, Eschrichtiidae,

779 Cetotheriidae and a clade including what Bisconti et al. (2013) called basal thalassotherian taxa.

780 Eschrichtiidae is the sister-group of Balaenopteridae and both form the monophyletic

781 Balaenopteroidea. Balaenopteroidea is the sister-group of a large clade including Titanocetus

782 sammarinensis, Cetotheriidae and basal thalassotherian taxa. Ti. sammarinensis is, in its turn, the

783 sister-group of Cetotheriidae and basal thalassotherian taxa. 
786 Our results support the monophyly of Balaenoidea with a noticeable difference with respect to 787 previously published literature (Cabrera, 1926; Bisconti, 2005; Churchill et al., 2012): 788 Morenocetus parvus falls outside Balaenidae + Neobalaenidae and represents the sister-group of 789 both families.

790 Nine synapomorphies support the monophyly of Balaenoidea. Three of them depends on the 791 structure of the skull: characters 37 (short exposure of interorbital region of the frontal because of 792 superimposition by the parietal), 54 (massive elongation of supraoccipital), and 55 (supraoccipital 793 is superimposed onto the interorbital region of the frontal). Moreover, character 47 (squamosal 794 dorsoventrally elongated) is also an exclusive synapomorphy of this clade.

795 Seventeen synapomorphies support the monophyly of Neobalaenidae + Balaenidae to the 796 exclusion of Morenocetus parvus. Three of them are unambiguous: characters 81 (short 797 dorsoventral height of the tympanic cavity), 82 (dorsoventrally compressed tympanic bulla), and 79883 (enlargement of epitympanic hiatus). Characters 11 (rostrum highly arched), 84 799 (anteroposteriorly short anterolateral lobe of tympanic bulla), 92 (dorsal exposure of mandibular 800 condyle), 95 (dorsoventral arc of dentary along the whole length of the bone), and 101 (cervical 801 vertebrae fused) represent additional ambiguous synapomorphies of the clade. Neobalaenidae 802 (including Caperea and Miocaperea) is the sister-group of Balaenidae (here including Balaena, 803 Balaenella, Balaenula and Eubalaena). The monophyly of Neobalaenidae is supported by 4 804 synapomorphies including a reversal in character 122 (complete infundibulum). Characters 50 805 (presence of squamosal cleft) and 75 (exposure of posterior process of petrotympanics in the lateral 806 view of the skull) are ambiguous synapomorphies as these characters (in different ways) are 807 observed in Balaenopteridae and Cetotheriidae, presumably as a result of convergent evolution. 
808 Four unambiguous synapomorphies support the monophyly of Balaenidae: characters 64 (massive 809 elongation of palatine posteriorly), 65 (posterior placement of pterygoid), 86 (sharply defined 810 groove for mylohyoidal muscle), and 122 (foramen ovale with incomplete infundibulum). Three 811 additional ambiguous synapomorphies are detected: characters 12 (transverse compression of 812 maxilla), 74 (long and thick roof of stylomastoid fossa), and 97 (strong anterior torsion of dentary).

813 Balaenidae is subdivided into two clades: one including Balaena and Balaenella and the other 814 including Balaenula and Eubalaena. The inclusion of Balaenella brachyrhynus within Balaena 815 casts some taxonomic problems as it either makes Balaena paraphyletic or suggests inclusion of 816 Balaenella within Balaena. Balaenella brachyrhynus and Balaena montalionis share an anteriorly 817 narrowed supraoccipital and a supraoccipital with transversely short anterior border; these 818 character states support their sister-group relationship. Unfortunately, a clear illustration of the 819 dorsal view of Balaena ricei is not available and it is difficult to understand whether this species 820 is really more closely related to Balaena montalionis and Balaenella brachyrhynus or to Balaena 821 mysticetus. From our results, B. mysticetus represents a separate lineage that diverged before the 822 other Balaena-like taxa (B. ricei, B. montalionis and Balaenella). A low number of 823 synapomorphies support the monophyly of the clade including Balaena and Balaenella. These 824 include the following two unambiguous synapomorphies: characters 116 (transverse compression 825 of anterior supraoccipital) and 120 (lateral projection of zygomatic process of the squamosal). 826 Additionally, two ambiguous synapomorphies are also found to support this clade; these include 827 characters 126 (posterior orientation of dorsoventrally developed squamosal body) and 132 (crest 828 present at parietal-squamosal suture). The sister-group relationship of Balaena montalionis and 829 Balaenella brachyrhynus is supported by one unambiguous synapomorphy (character 117: squared 
830 anterior border of supraoccipital) and one ambiguous synapomorphy (character 118: short anterior

831 border of supraoccipital).

832

833 Relationships of Eubalaena

834 Confirming previously published hypotheses (Bisconti, 2000, 2005a; Churchill et al., 2012), our 835 analysis resulted in the monophyly of a clade including Balaenula and Eubalaena (Fig. 12). The 836 clade including Eubalaena and Balaenula is the sister-group to the Balaena + Balaenella clade.

837 Balaenula is the sister-group of Eubalaena. Three unambiguous and one ambiguous

838 synapomorphies support this clade. The unambiguous synapomorphies include characters 123

839 (transverse orientation of supraorbital process of the frontal in lateral view), 129 (curvature of 840 rostrum with horizontal proximal part), and 130 (concavity on the anterior border of nasal).

841 Character 118 (transversely wide anterior border of supraoccipital) was also found to support this

842 clade (ambiguous synapomorphy).

843 Eubalaena shinshuensis is the first Eubalaena species to branch; the Eubalaena sp. from the Late

844 Pliocene of Tuscany is the sister-group of the living Eubalaena species + E. ianitrix and its 845 inclusion on a separate ramus suggests that it could be a different Eubalaena species of its own. 846 Eubalaenajaponica and E. australis branch before E. ianitrix and E. glacialis, the two latter being 847 sister-groups.

848 Only one unambiguous synapomorphy was found to support the monophyly of the right whale 849 genus Eubalaena; character 115 (presence of a dome on the supraoccipital). We think that this 850 reduced morphological support for the well-established Eubalaena genus is due to the fact that 851 most of the characters previously used to support its monophyly are shared with Balaenula.

852 Eubalaena shinshuensis from the Messinian of Japan was found to be the earliest-diverging right 
853 whale species of the genus; the Pliocene Eubalaena sp. from Tuscany is the sister-group of the

854 living Eubalaena species + E. ianitrix. The monophyly of the Eubalaena sp. from Tuscany and

855 the crownward Eubalaena species was supported by one unambiguous synapomorphy (character

856 127: squared exoccipital in lateral view) and one ambiguous synapomorphy (character 126:

857 vertical orientation of squamosal body).

858 The clade including the living Eubalaena species and E. ianitrix is supported by 5 unambiguous 859 synapomorphies (125: parietal-frontal suture with distinctive anteroventral corner; 131: short

860 nasals; 133: parietal spreads on the supraorbital process of the frontal; 140: presence of vascular 861 groove on posterior part of pars cochlearis; and 141: evident pyramidal process posterior to 862 perilymphatic foramen) and 8 ambiguous synapomorphies (114: sagittal concavity on 863 supraoccipital; 134: anterior protrusion of parietal-squamosal suture; 135: prismatic posterior 864 process of petrosal; 138: transversely elongated pars cochlearis; 143: long transverse process of 865 the atlas; 146: highly concave anterior and posterior borders of humerus; 147: globular humeral 866 head; 150: superior corner of olecranon reduced-to-absent; and 151: reduced-to-absent coracoid 867 process in scapula) (Fig. 13).

868 Eubalaena australis was found to be more closely related to E. ianitrix + E. glacialis than E. 869 japonica. The sister-group relationship of E. glacialis with E. ianitrix + E. glacialis was supported 870 by two unambiguous synapomorphies: characters 139 (crista transversa exits from internal 871 acoustic meatus) and 152 (transverse orientation of tyrohyoidal processes). It is noticeable that 872 none of these characters is preserved in the holotype of E. ianitrix and the placement of this species 873 in this precise position in the cladogram relies on ACCTRAN optimization of the morphological 874 transformations operated by TNT. The monophyly of the clade Eubalaena ianitrix + E. glacialis 
875 is supported by a single ambiguous synapomorphy: character 121 (presence of pterygoid in 876 temporal fossa).

877

878 Stratigraphic Consistency Index

879 The calculation of the Stratigraphic Consistency Index shows that the degree of agreement of the 880 branching pattern with the stratigraphic occurrence of the taxa is exceptionally high. The SCI 881 depends on (1) the number of well-resolved nodes and (2) the number of stratigraphically 882 consistent nodes. In the hypothesis of phylogeny presented in this paper, the maximum number of 883 nodes is 40 (number of OTUs minus 2) and the number of stratigraphically consistent nodes is 33.

884 The SCI is thus 0.825 .

885

886

Divergence dates of balaenoid clades

887 In Fig. 14 the hypothesis of phylogeny for Balaenoidea proposed in the present paper is plotted 888 against the stratigraphic age of the included OTUs. In the Figure, branch lengths are inferred from 889 the phylogenetic relationships of the taxa and from the stratigraphic ages of the representative 890 fossil record of each OTU.

891 The age of Miocaperea pulchra suggests that the origin of the clade including Balaenidae + 892 Neobalaenidae is older than Tortonian (early Late Miocene). Unfortunately, given that 893 Morenocetus parvus falls outside Neobalaenidae + Balaenidae, it is not possible to be sure about 894 the precise age of origin of these families. Indeed, as the stratigraphic occurrence of M. parvus is 895 limited to the Burdigalian (late Early Miocene), the age of origin of Neobalaenidae and Balaenidae 896 may be constrained to a time interval between Burdigalian and Tortonian. 
897 The fossil record of Balaena-like species does not extend before Zanclean (Early Pliocene). The

898 stratigraphic occurrences of Balena montalionis, B. ricei and Balaenella brachyrhynus suggest

899 that an expansion of the paleobiogeographic range of Balaena-like taxa was attained during the

900 earliest part of the Pliocene with invasion of Mediterranean, North Atlantic and North Sea. The

901 sister-group relationship of Balaena mysticetus and the other Balaena-like taxa suggest that the

902 direct ancestor of the living bowhead whale originated around the Zanclean or slightly earlier and

903 possibly quickly invaded the Arctic region, leaving us more limited possibilities to find fossil

904 records relevant for the morphological transition towards the extant species.

905 The stratigraphic age of Eubalaena shinshuensis is the most crucial point in the present

906 reconstruction of the divergence dates of balaenoid taxa. In fact, as the occurrence of this species

907 is from the Messinian, the origin of the whole Balaenula + Eubalaena clade must be traced back

908 to at least the latest Miocene. This means that the separation of the living right whales from their

909 closest living relative (i.e., Balaena mysticetus) is from 7-to-5.4 million years ago which

910 significantly increases the hypothesized divergence date based on McLeod et al. (1993) and

911 reduces to one-third of the hypothesized divergence date based on Bisconti (2005b) and Santangelo

912 et al. (2005). The impact of this new divergence date on the reconstruction of the demographic

913 history of the right whales based on genetic measures of diversity will be analysed elsewhere.

914 As far as the origins of the living Eubalaena species is concerned, the Messinian age of E.

915 shinshuensis suggests that the origin of the genus Eubalaena should be found at least in the latest

916 Miocene. The stratigraphic occurrences of the Eubalaena sp. from Tuscany and E. ianitrix

917 constrain the origin of the living right whale species to at least the Piacenzian. Therefore, we

918 estimate that the modern Eubalaena species originated in a period between 3.5 and 2.6 Ma. As we

919 will show in another paragraph, it is more difficult to determine a chronological placement for the 
920 origin of the northern right whale E. glacialis because the origin of this species could be due to a 921 process of phyletic transformation from E. ianitrix, occurring in a time interval ranging from the

922 Piacenzian to the Pleistocene.

923 In summary, the stratigraphic distribution of the main evolutionary events of Balaenoidea are 924 presented in Fig. 13. Following our phylogenetic analysis and the computation of stratigraphic 925 ages of the included OTUs, the origin of Balaenoidea should be traced at least as far as the 926 Burdigalian (age of Morenocetus parvus). The origin of the living families (Neobalaenidae and 927 Balaenidae) occurred before the Tortonian (age of Miocaperea pulchra). The splitting between the 928 Balaena-like and the Balaenula + Eubalaena clades occurred before the Messinian (age of 929 Eubalaena shinshuensis). The origin of the modern Eubalaena radiation (including E. ianitrix) 930 dates at least from the Piacenzian. The separation between the living right whale species and their 931 extant relative (Balaena) dates at least from the earliest Messinian (c. $7 \mathrm{Ma})$.

Discussion

Body size estimate

936 The methods we used to estimate the size of Eubalaena ianitrix resulted in a total body length 937 included between 6 and $7 \mathrm{~m}$ and a body mass of c. 20 t. The statistical methods used have their 938 shortcomings in that most of them were not tested on species of the genus Eubalaena. The ratio 939 between skull length and body length is a general estimate of body proportions in Balaenidae used 940 by several authors based on observations of mounted skeletons, and killed and stranded animals 941 (Koshi et al., 1993; Tomilin, 1967; Omura, 1958). The ratio between supraoccipital length and 942 total skull length was used by Bisconti (2002) based on a small dataset of right whale 
943 measurements and its correlation coefficient $\mathrm{R}^{2}$ is rather low; therefore, the body size estimate

944 generated by this method must be considered as preliminary pending the inclusion of more

945 measurements in the dataset. However, all the methods used converge toward a total body length

946 of 6-to-7 $\mathrm{m}$ and we think that this result should be close to the true length of the living animal. At

947 present, we have no reason to suppose that a kind of systematic error occurred in a consistent

948 manner to provide a systematically wrong result based on all the methods used.

949 It is unclear whether this size represents the maximum length of E. ianitrix because nothing is

950 known about its individual variation. If compared with other balaenids, it represents a medium-

951 sized species (see Supplementary Table S2 and Supplementary Figure S1). More precisely, it is

952 the only medium-sized species within the Eubalaena clade (Supplementary Figure S2), suggesting

953 that its medium size is a derived condition. The origin of the size reduction in E. ianitrix may be

954 related to the warmer temperature of the southern portion of the North Sea during the deposition

955 of the Lillo Formation (latest Zanclean-early Piacenzian; Laga et al. 2006). In fact, the Kruisschans

956 Sands Member of the Lillo Formation (in which the holotye skull of E. ianitrix was found)

957 deposited in a shallow, low-energy environment, where molluscs indicate some degree of cooling,

958 but where the palynological assemblage suggests mild-temperate to warm marine conditions

959 (Marquet, 1993; Louwye et al., 2004; De Schepper et al., 2009). However, it is still unknown

960 whether E. ianitrix inhabited permanently the southern North Sea.

961 In the extant Eubalaena glacialis and E. australis, a total body length of less than 7 m corresponds

962 to the length of individuals less than one year old (George et al. 2016; Fortune et al. 2012). The

963 holotype skull of Eubalaena ianitrix, however, shows sutural morphologies and general robustness

964 inconsistent with the general osteological features of newborn and early juvenile individuals (e.g.,

965 occipital joints not closed, presence of spongy bone; see Walsh \& Berta, 2011). Rather, its robust 
966 muscular attachments on the supraoccipital and the degree of fusion at the frontoparietal (coronal)

967 and parietal-squamosal sutures suggests that its age was older than 1 year. It is impossible to assess

968 at which stage of its life cycle it died as nothing is known about intraspecific variation in skull and

969 body length in E. ianitrix. Future discoveries of new specimens from different age classes will help

970 providing an overview of the ontogenetic variation in body size in this newly discovered species.

971 The estimate of the body mass obtained in the present work is at odds with published records

972 regarding the relationships of body mass and total body length in extant Balaenidae. Fortune et al.

973 (2012) reported weights ranging from 0.7 to $11 \mathrm{t}$ for 6-9 $\mathrm{m}$ long bowhead whales, while Trites \&

974 Pauli (1998) estimated masses ranging from 19 to $24 \mathrm{t}$ for 16-18 $\mathrm{m}$ long northern and southern

975 right whales. Our result of c. 20 for the 6-7 m long Eubalaena ianitrix appears overestimated,

976 suggesting that more research is needed to develop more accurate statistical methods for inferring

977 body size and body mass information in Balaenidae.

978

979 Phylogeny: Relationships of Balaenidae

980 Phylogenetic analyses of Balaenidae were published by several authors in the last 25 years.

981 McLeod et al. (1993) were the first to publish a phylogenetic tree based on manual manipulation

982 of morphological character states. They found a monophyletic Balaenoidea and a sister group

983 relationship between Neobalaenidae and a clade formed by Balaenidae and Eschrichtiidae. The

984 sister-group relationship of Balaenidae and Eschrichtiidae was not confirmed by subsequent

985 phylogenetic works.

986 Bisconti (2000) performed the first computer-assisted cladistic analysis of Balaenidae, retrieving

987 a monophyletic Balaenoidea and a monophyletic Balaenidae. Within Balaenidae, Bisconti (2000)

988 found two different clades: one including the genus Balaena and the other including Eubalaena, 
989 Balaenula and Morenocetus. After a substantial re-discussion of the fossil record of Balaenidae

990 (Bisconti, 2003) and of previously published phylogenetic analyses, Bisconti (2005a) published a

991 new phylogenetic analysis resulting in a monophyletic Balaenoidea and a monophyletic

992 Balaenidae; two clades were recovered in Balaenidae: one included Morenocetus, Balaenella and

993 Balaena and the other included Eubalaena and Balaenula. These finds were substantially

994 confirmed by Churchill et al. (2012) after an extensive reanalysis of the morphological evidence

995 of the phylogeny of Balaenidae.

996 Numerous other works on the phylogeny of mysticetes were published in the last decades that

997 included balaenids, but not explicitly focused on Balaenidae. However, it is important to consider

998 these works as they provide information about the sister-group relationships of Balaenidae and

999 other mysticete taxa. While most of the morphology-based works agree that Balaenidae and

1000 Neobalaenidae are sister-groups (Bisconti, 2015 and literature therein; Boessenecker \& Fordyce,

1001 2016), several recent papers did not support the monophyly of Balaenoidea with Neobalaenidae as

1002 sister group of Balaenopteroidea (see Gol'din et al., 2014 and literature therein) or as part of

1003 Cetotheriidae (e.g., Marx \& Fordyce, 2015 and literature therein). The placement of Caperea

1004 marginata and Miocaperea pulchra within Cetotheriidae depended upon peculiar treatments of

1005 some characters related to the shape and orientation of the squamosal, the elongation of the

1006 supraoccipital and the reduction of the ascending process of the maxilla. Criticisms to this

1007 approach were published by El Adli et al. (2014) and Bisconti (2015) suggesting that the Marx \&

1008 Fordyce (2015) dataset should be revised. Marx \& Fordyce (2016) provided a subsequent version

1009 of such a dataset that shows substantially the same characteristics, as it does not include character

1010 states describing the topological relationships of the bones forming the skull vault in Balaenidae

1011 and Neobalaenidae. The proposed sister-group relationship of Neobalaenidae and 
1012 Balaenopteroidea + Cetotheriidae depends on (1) inclusion of molecular data or (2) emphasis on 1013 rorqual-like characters observed in Caperea marginata (i.e., long forelimb, presence of dorsal fin, 1014 and presence of ventral throat grooves).

1015 The problem of using molecular data to infer the phylogenetic relationships of clades mainly 1016 formed by fossil taxa (e.g., Hominidae, Mysticeti) has been addressed by several authors and this 1017 is the precise case of mysticetes where most of the described species are now extinct and cannot 1018 be used for DNA sequencing and analysis. Even if molecular analyses may include thousands of 1019 character states (base pairs from DNA sequences), the lack of data from most of the taxa belonging 1020 into the clade may be a serious problem as an enormous number of character states cannot be

1021

1022

1023

1024

1025

1026

1027

1028

1029

1030

1031

1032

1033

1034 scored and must be inferred by the computer program used for the analysis. The accuracy of phylogenetic reconstructions based on molecular data for clades mainly formed by extinct taxa tends to be lower than that based on morphological data (Heath et al., 2008; Wagner, 2000). This suggests that emphasis should be given to morphological rather than molecular data in the inference of the phylogeny of mysticetes.

Aside from that, it must be said that taxonomic uncertainties, problems with character descriptions and coding, and the discovery of large amounts of homoplasy in morphological datasets have plagued morphological attempts to infer phylogenetic relationships in mysticetes in the last twenty years (Deméré et al., 2005; Bisconti, 2007). Our effort to reduce dataset homoplasy was successful only in part. In fact, after the exclusion of evident homoplastic characters from our morphological dataset, the number of usable character states dropped down and our morphological evidence could provide only strong support for only some clades. Most of the species-level sister group relationships are thus supported by reduced numbers of synapomorphies. In this sense, what we observe in balaenid phylogenetics resembles what was observed in complicated analyses of 
1035 evolutionary radiations occurring in relatively recent times (e.g., cichlid fishes and hominins; e.g.,

1036 Seehausen, 2006; Haile-Selassie et al., 2016) with the important difference that the evolutionary

1037 radiation of Balaenidae occurred in a longer time interval. However, studies of DNA substitution

1038 rates interestingly showed that mysticete DNA evolves much more slowly than that of other

1039 mammals (Rooney et al., 2001); therefore, only limited morphological change should be expected

1040 to occur in this group in the last few million years. This expectation is somewhat confirmed by the

1041 substantial stasis detected in the last 10 million years of neobalaenid evolution (Tsai \& Fordyce,

1042 2015; Bisconti, 2012) and by the small amount of morphological diversity observed in Balaenidae

1043 as discussed in this work. The reasons of the slow evolutionary pace in Balaenidae are not

1044 completely understood; one character that could be correlated is the evolution of increased

1045 individual longevity, demonstrated to be linked to DNA preservation (Jackson et al., 2009; Keane

1046 et al., 2015), which, in its turn, should reduce the accumulation of mutations preventing the

1047 evolution of phenotypic diversity.

1048

1049 Phylogeny: intra-family relationships within Balaenidae

1050 Published studies specifically directed at discovering phylogenetic relationships of Balaenidae

1051 recently converged towards the subdivision of this family into two sub-clades: a clade including

1052 Balaena and Balaenella and a clade including Balaenula and Eubalaena. These two groups are

1053 well supported by morphological characters and correspond to two different skull structures (as

1054 evidenced by Miller, 1923; Kellogg, 1928; McLeod et al., 1993; Bisconti, 2005a).

1055 The contribution of the postcranial skeleton to the support for these clades is rather scanty but, for

1056 the first time, we detected that: (1) the dorsal transverse process of the atlas is dorsoventrally

1057 enlarged in Eubalaena and reduced in Balaena (including B. mysticetus and B. ricei), (2) the 
1058 ventral transverse process of the atlas is long and forms a ventral corner in Balaena but is short

1059 and squared in Eubalaena, (3) the humerus is long and slender in Balaena while in Eubalaena it

1060 is shorter and with a more globular head, and (4) the dorsal corner of the olecranon process of the

1061 ulna is conspicuous in Balaena but reduced to absent in Eubalaena.

1062 The four characters outlined above could be useful to suggest phylogenetic and taxonomic 1063 affinities of fossils of uncertain position because of their poor preservation. This is the case of a 1064 number of partial skeletons from the Pliocene of Italy (Bisconti, 2003; Chicchi \& Bisconti, 2014; 1065 Cioppi, 2014; Bisconti \& Francou, 2014; Manganelli \& Benocci, 2014; Sarti \& Lanzetti, 2014) 1066 that should be reassessed based on this new evidence.

1067 As mentioned above, the sister-group relationship of Balaena montalionis and Balaenella 1068 brachyrhynus raises particular problems as the inclusion of Balaenella within Balaena would 1069 either make the latter paraphyletic, or would imply the assignment of Balaenella to Balaena. 1070 However, we feel that it is premature to choose one of the above options, as some morphological 1071 data from Balaena ricei were not available for this study (i.e., precise sutural pattern between 1072 parietal and frontal and between parietal and squamosal, and shape of the anterior end of the 1073 supraoccipital); this makes relationships within the Balaena-like subclade still biased by some 1074 uncertainty. However, the close relationship of B. montalionis and B.lla brachyrhynus seems well 1075 supported by the shared squared anterior border of the supraoccipital and the transverse 1076 compression observed in the anterior half of the lateral borders of the supraoccipital. The point, 1077 here, consists in understanding if Balaena ricei is more closely related to Balaena mysticetus or to 1078 the B. montalionis + B.lla brachyrhynus pair; more data are needed about the morphology of $B$. 1079 ricei to solve this question. 
1080 Among right whales, Eubalaena shinshuensis is the first to branch off, due to the primitive sutural

1081 pattern observed in the skull of this Messinian species; the following branch is occupied by the

1082 Piacenzian Eubalaena sp. from Tuscany, due to the plesiomorphic parietal-squamosal suture and

1083 to a peculiar supraoccipital morphology. More interesting are the relationships of the living

1084 Eubalaena species and E. ianitrix. From our work, E. japonica is the earliest-diverging species

1085 among the living right whales, with E. australis and E. glacialis more closely related to each other.

1086 This result contradicts molecular studies that suggested that E. australis diverged earlier and that

1087 E. glacialis and E. japonica are sister-groups (e.g., Gaines et al., 2005; Rosenbaum et al., 2000).

1088 Also the DNA-based phylogeny of species of lices parasitizing living Eubalaena species lends

1089 support to the molecular hypothesis of relationships for right whales (e.g., Kaliszewska et al., 1090 2005) thus suggesting that E. glacialis is the earliest-diverging Eubalaena species. However, these 1091 analyses did not include data from fossil right whales such as E. shinshuensis, E. ianitrix, and the 1092 Eubalaena sp. from Tuscany and did not take into account the fossil histories of the different lice 1093 species; therefore, they could be unable to retrieve correct results (in accordance with Heath et al., 1094 2008; Wagner, 2000). Moreover, assuming an early branching of E. glacialis in the phylogeny of 1095 the living right whales implies that reticulate biogeographic histories have occurred between the 1096 southern and the North Pacific Eubalaena species to account for the peculiar genetic patterns 1097 observed in cyamid lices (Kaliszewska et al., 2005).

1098

1099 Divergences of the living right whale species

1100 Divergence ages of living balaenid species are important for the reconstructions of the 1101 demographic histories of these taxa in the context of conservation biology. Divergence dates are 1102 used in equations dealing with the genetic diversity of the living populations to assess whether 
1103 living species suffered of genetic bottlenecks due to environmental change or human impact (e.g.,

1104 Rosenbaum et al., 2001). Fossil calibrations of divergence dates are necessary to constrain the pace

1105 of molecular clocks in order to get correct results in terms of assessments of genetic diversity and

1106 evolution (Quental \& Marshall, 2010).

1107 Several works have provided estimates of divergence ages of balaenid species. McLeod et al. 1108 (1993) suggested a separation date between Eubalaena and Balaena of c. 4.5 Ma based on analysis 1109 of the balaenid fossil record. This assessment was used by Rosenbaum et al. (2001) to analyse the 1110 genetic diversity of the living bowhead whale, Balaena mysticetus, with the conclusion that this 1111 species did not suffer of population bottlenecks due to human whaling activities. Bisconti (2005b) 1112 and Santangelo et al. (2005) questioned this conclusion based on the phylogenetic analysis 1113 provided by Bisconti (2005a); the latter opened the possibility that the divergence between 1114 Eubalaena and Balaena occurred in the Early Miocene. This conclusion resulted from the 1115 placement of Morenocetus parvus as sister-group of the Balaena-like subclade to the exclusion of 1116 the Balaenula + Eubalaena subclade (Bisconti 2005a) thus providing a divergence date of Balaena 1117 and Eubalaena of more than $20 \mathrm{Ma}$.

1118 Subsequent analyses did not confirm this result as molecule-based and morphology-based works 1119 suggested later divergence dates (e.g., Sasaki et al., 2007; Churchill et al., 2012) and placed the 1120 divergence of Balaena and Eubalaena in a time interval ranging from c. 4 to c. 7 Ma. The 1121 phylogenetic analysis of Cyamus lices confirms a divergence at c. 6.6 Ma for the living right whale 1122 and bowhead whale species (Kaliszewska et al., 2005).

1123 The phylogenetic analysis of the present work (Figs 12 and14) reinforces a minimum late Miocene 1124 divergence (Messinian: c. 7-5.4 Ma) based on the age of the earliest diverging Eubalaena species 1125 (i.e., E. shinshuensis). In fact, an earlier divergence age is not unlikely, considering that (1) based 
1126 on the present work, the separation between Balaenidae and Neobalaenidae dates from at least the

1127 Tortonian (c. $10 \mathrm{Ma}$ ) and (2) the separation of the Balaena-like subclade from the Balaenula +

1128 Eubalaena subclade is deep in time and originates from the very origin of Balaenidae (Bisconti,

1129 2005a; Churchill et al., 2012; this work).

1130 How the reconstructions of the demographic histories of balaenids will be impacted by a Late

1131 Miocene age of divergence between Eubalaena and Balaena is outside the scope of the present

1132 paper. However, we suggest here that the past estimates of genetic diversity in right and bowhead

1133 whale populations should be considered with caution as those were based on underestimated

1134 (McLeod et al., 1993) or overestimated (Bisconti, 2005b; Santangelo et al., 2005) divergence ages.

Possible ancestor-descendant relationships between Eubalaena ianitrix and Eubalaena glacialis

1137

1138

1139

1140

1141

1142

1143

1144

1145

1146

1147

1148

1149

There is not a commonly accepted method to infer ancestor-descendant relationships (ADRs) in phylogenetics as it is supposed that only in exceptional cases such a relationship can be detected in the fossil record (Paul, 1992). The most usual recommendation to those who try to recover ADR from the fossil record consists in being sure that a reasonably complete sample is available for the past diversity of the investigated group. While it is certain that this is not the case for fossil cetaceans, some attempts to reconstruct ADRs in this order were attempted in the past with a diversified array of methods.

Uhen \& Gingerich (2001) provided an ADR for Chrysocetus healyorum and Neoceti (Mysticeti + Odontoceti). They used a stratocladistic approach in three steps: (1) they performed a traditional computer-assisted, morphology-based cladistics analysis retrieving a set of resulting cladograms; (2) they added a stratigraphic character and manipulated the initial hypothesis of relationships by hand in order to explore whether $C$. healyorum could be the direct ancestor of Neoceti; (3) they calculated a new set of cladograms via a computer-assisted algorithm. They found one most 
1150 parsimonious tree in which $C$. healyorum was placed as direct ancestor of Neoceti. In the

1151 subsequent discussion, they suggested that newly discovered advanced archaeocete taxa could fit

1152 the ancestor position for Neoceti in a better way than $C$. healyorum thus giving this taxon a 1153 temporary ancestor status.

1154 More recently, Tsai \& Fordyce (2015) suggested an ADR for Miocaperea pulchra and Caperea 1155 marginata based on a combination of cladistic analysis of traditional OTUs + juvenile individuals

1156 of $C$. marginata and by providing a discussion on the impact of the morphology of juvenile 1157 characters in phylogeny reconstruction. Apart from cetaceans, ADR were also hypothesized for 1158 the fur seal Callorhinus (Boessenecker 2011), great white sharks (Ehret et al. 2012), and the 1159 dinosaur Triceratops (Scannella et al. 2014)

1160 All of these methods have their own merits and shortcomings; Uhen \& Gingerich (2001) realized 1161 a systematized search for the most parsimonious solutions but their results were limited by 1162 uncertainties about the completeness of the relevant fossil record; Tsai \& Fordyce (2015) used data 1163 from a hotly debated source of data (i.e., juvenile and embryonic specimens) (e.g., Hall, 1996 and 1164 literature therein). Apart from that, however, the search for ADRs is always worth doing, as it 1165 potentially gives information on natural evolutionary processes.

1166 Here, we suggest that an ADR should be proposed for the Eubalaena ianitrix and Eubalaena 1167 glacialis species pair. We support our hypothesis of relationships based on what follows:

1168 (1) E. glacialis and E. ianitrix are phylogenetically more closely related than all the other 1169 species belonging to Eubalaena; they share one peculiar synapomorphy that is not 1170 observed in any other Eubalaena species (i.e., presence of the pterygoid in the temporal fossa). 
1172

1173

1174

1175

1176

1177

1178

1179

1180

1181

1182

1183

1184

1185

1186

1187

1188

1189

1190

1191

1192

1193

1194

(2) Molecular studies suggest that the branch of E. glacialis has been separated from the other living right whale species for a long time (up to 3 million years). This long time interval excludes the possibility of an arrival in the North Atlantic due to a Plesistocene or Holocene invasion from the North Pacific or the southern right whale species (Kaliszewska et al., 2005). Thus, it is highly likely that E. glacialis originated in that portion of the northern hemisphere that includes the North Atlantic and the North Sea.

(3) E. glacialis and E. ianitrix share part of their geographic distribution. Even if only one specimen of E. ianitrix is known up to now, its geographic occurrence is included within the geographic range of E. glacialis.

(4) The geographic area that encompasses the distribution of E. ianitrix and E. glacialis underwent extensive environmental change during the past 1.5 million years (Zachos et al., 2001), supporting the hypothesis that selective regimes could have been active there implying phenotypic evolution in previously established populations. In particular, the temperature decline observed in the whole northern hemisphere during the Pleistocene could have been the driver of organismal responses that can be described (in part, at least) by the Bergmann's rule (i.e., increasing body size).

(5) Assuming a species longevity of 2 million years (Fordyce \& de Muizon, 2001; Steeman et al., 2009), and hypothesizing that Eubalaena glacialis became a well-defined species around the Pliocene-Pleistocene boundary, there may be a time interval in which E. ianitrix and the earliest individuals of E. glacialis co-occurred in the same area where the morphological transition happened. Unfortunately, the estimated species longevity mentioned above is only based on the observation that the fossil record of the living mysticete species does not exceed c. 2 million years (Fordyce, 2002). Based on molecular 
data, alternative analyses suggest longer species durations (see Pastene et al. 2007 for Balaenoptera acutorostrata and Sasaki et al. 2005 for many species of baleen-bearing whales; these studies suggest divergence dates of some living species exceeding 2 million years). This does not contradict our proposed sympatry hypothesis for E. glacialis and E. ianitrix; rather, hypothesizing longer species duration would reinforce this hypothesis. To our knowledge, no molecule-based work supports a species duration shorter than 2 million years for extant baleen-bearing whales.

(6) Bearing in mind the paleoenvironmental changes that occurred in the northern hemisphere

(7) From a skeletal morphology perspective, if a phyletic transformation of E. ianitrix into $E$. extant E. glacialis to reach more than $20 \mathrm{~m}$ in length at maturity (Tomilin, 1967) against the $c .7 \mathrm{~m}$ of E. ianitrix (consistent with Bergmann's rule in a colder environment), (ii) possible allometric adjustments of bone proportions (this is a direct consequence of point 1), (iii) loss of the crest at the parietal-squamosal-supraoccipital suture, and (iv) change in the orientation of the posteromedial corner of the palatine. The crest at parietal-squamosalsupraoccipital suture appears to have been lost in the common ancestor of E. glacialis $+E$. ianitrix + E. japonica + E. australis clade and its presence in E. ianitrix is to be interpreted as a reversal to a plesiomorphic condition. The same applies to the protrusion of the posteromedial corner of the palatine. The recurrent evolution of these two characters suggests that some homoplasy occurred in the above clade in the last few million years. 
1218

1219

1220

1221

1222

1223

1224

1225

1226

1227

1228

1229

1230

1231

1232

1233

1234

1235

1236

1237

1238

1239

1240

(8) Current genetic evidence supports the view that three distinct species of right whales inhabit three different ocean basins (Malik et al., 2000; Rosenbaum et al., 2001): Eubalaena glacialis in the North Atlantic and adjacent waters, E. japonica in the North Pacific, and E. australis in the Southern Ocean. Balaenoid whales perform a particular feeding behavior directed at capturing calanoid copepods; this feeding behavior is known as continuous ram feeing (Sanderson \& Wassersug, 1993) or skim feeding (Pivorunas, 1979). In the northern hemisphere, there is a geographic separation between the skim feeding species: the bowhead whale inhabits Arctic waters, while the right whales inhabit more temperate waters and the two right whale species of the northern hemisphere are separated by the Eurasia and thus do not compete for food or reproductive areas. In the southern hemisphere, the two skim feeding species are geographically separated as the southern right whale feeds around Antarctica while the pygmy right whale is restricted to more temperate waters; apparently, there is no competition between these species for food or reproductive areas. It appears, thus, that only one skim feeding species is "allowed" to live in a given ocean basin, and we may hypothesize that the pattern was not different in the past million years. For this reason, we may expect that only one or a few right whale species occupied a given geographic area in time intervals of $c .2$ million years (mean duration of a marine mammal species; see above). This suggests that, paradoxically, the taxonomic sample of the right whale diversity in the Late Pliocene of the northern hemisphere is rather complete. This inference is also confirmed by the high value of the SCI obtained here, suggesting that most of the phylogenetic relationships presented here can be explained without the need for long ghost lineages. This inference fills the requests for a dense taxonomic sampling in the taxa under investigation and allows us to give further 
support to our hypothesis of ADR for Eubalaena ianitrix and E. glacialis. It must be said,

1242

1243

1244

1245

1246

1247

1248

1249

1250

1251

1252

1253

1254

1255

1256

1257

1258

1259

1260

1261

1262

1263

however, that the current diversity of right and bowhead whales includes only large-sized species, whereas, in the Pliocene, large-sized and small-sized balaenid species are demonstrated to have been sympatric (Bisconti, 2003). Moreover, several studies have addressed the impact of shark predation on Pliocene right whales, suggesting some differences in the trophic webs of the Pliocene oceanic basins with respect to modern times. The ecological meanings of these differences are still not fully understood, potentially impacting our hypothesis regarding the taxonomic completeness of the balaenid fossil record.

(9) In a way to test the ADR for Eubalaena ianitrix and E. glacialis, we followed the stratocladistic approach of Uhen \& Gingerich (2001). The taxon x character matrix and the single most parsimonious tree were taken to MacClade (Maddison \& Maddison, 2000). First, without the addition of a stratigraphic character, the ADR for E. ianitrix and $E$. glacialis was demonstrated to increase the tree length of two steps, as compared to the original tree length with a sister-group relationship. After addition of the stratigraphic character (see Supplementary Information) and without any other modification of the topology, the difference in tree length decreased from two steps to one step, meaning that the sister-group relationship was still the most parsimonious, but that stratigraphic data, namely the Piacenzian age of E. ianitrix, made the difference less significant. Swapping branches by hand, ADR for E. ianitrix and E. glacialis was found more parsimonious than a sister-group relationship only with (i) E. shinshuensis being more stemward than Balaenula astensis, and (ii) the three extant Eubalaena species forming a clade, with $E$. ianitrix as their last common ancestor. The need for such changes in topology may indicate 
1264

1265

1266

1267

1268

1269

1270

1271

1272

1273

1274

1275

1276

1277

1278

1279

1280

1281

1282

1283

1284

1285

1286 that E. ianitrix is not the ancestor of E. glacialis. However, we think that such a pattern is strongly impacted by the scanty Pliocene balaenid fossil record in some areas (for example the North Pacific and the Southern Ocean). Pending the future discovery of fossil relatives of E. australis and E. japonica, stratocladistic analyses will most likely not be able to unambiguously discriminate ADR and sister-group relationships for E. ianitrix and $E$. glacialis.

\section{Conclusions}

We re-described specimens previously referred to 'Balaena' belgica and found what follows.

(1) The cervical complex RBINS M. 881 (IG 8444) that was originally designated as type of 'Balaena belgica by Abel (1941) is poorly preserved and does not show diagnostic characters below the family level; therefore, we assign it to Balaenidae gen. et sp. indet.; this decision makes 'Balaena' belgica, and its recombination nomina dubia.

(2) The fragment of maxilla RBINS M. 880 lacks crucial diagnostic characters and cannot be assigned to any of the described balaenid genera and species; it is therefore assigned to Balaenidae gen. et sp. indet.

(3) The morphology of the humerus RBINS M. 2280 is closer to that of Eubalaena glacialis as compared to Balaena mysticetus in the shape of the articular facet for the olecranon process of the ulna, in the overall shape of the deltoid tuberosity, and in the shape of the posterior border of the diaphysis. However, it differs from E. glacialis and other extant Eubalaena species in the elongation of the straight posterior border of the diaphysis; it is therefore assigned to Eubalaena sp. indet. This humerus corresponds to a large individual 
reaching a total body length over $16.5 \mathrm{~m}$; it represents the first report of a gigantic right whale in the fossil record of the North Sea.

(4) The neurocranium RBINS M. 879a-f represents the holotype of the new species Eubalaena ianitrix. This species is described and analysed into a phylogenetic context. From a

(6) The separation of Eubalaena from Balaena is estimated to have occurred around $7 \mathrm{Ma}$ and E. ianitrix.

(5) Our phylogenetic analysis also retrieved a monophyletic Balaenoidea, with Morenocetus parvus as the earliest stem balaenoid taxon, and with Neobalaenidae being the sister-group of Balaenidae. Two clades are observed within Balaenidae: one including Balaena-like taxa (genera Balaena and Balaenella) and the other including Balaenula and Eubalaena. The Messinian E. shinshuensis is the earliest diverging Eubalaena species; the Eubalaena sp. from Tuscany is the sister-group of a clade including all the living Eubalaena species (minimum age). The origins of the living right whale species should be chronologically constrained to the Piacenzian (Late Pliocene: at least between 3.6 and 2.6 ma). Judging from supporting synapomorphies, stratigraphic ranges and ecological requirements, it is suggested that Eubalaena ianitrix is the direct ancestor of E. glacialis, the latter is proposed to have evolved via phyletic transformation, through body size increase and allometric adjustments during the temperature decline of the latest Pliocene and Pleistocene. 
1311 The authors wish to thank Annelise Folie, Alain Drèze and Cécilia Cousin (all at RBINS, Brussels)

1312 for providing access to the specimens and for assisting in the transport of these heavy bones;

1313 Stéphane Berton and Marc Spolspoel (both at RBINS, Brussels) for their help when restoring the 1314 specimens studied here and when taking photos of part of the specimens illustrated here, 1315 respectively. Many thanks are due to Richard Monk, Eric Brothers, Eileen Westwig, Maria 1316 Dickson, and Nancy Simmons (all at AMNH, New York), Graham and Margaret Avery and 1317 Leonard Compagno (all at IZIKO, Cape Town), Reinier Van Zelst, John De Vos, Steven Van Der 1318 Mije and Wendy Van Bohemen (all at Naturalis, Rotterdam) for granting access to specimens under their care. Many thanks are due to Mark D. Uhen (George Mason University, Fairfax), Robert W. Boessenecker (College of Charleston) and J.G.M. Thewissen (PeerJ editor) for their reviews that highly enhanced the quality and the clarity of the manuscript.

\section{References}

Abel O. 1941. Vorläufige Mitteilungen über die Revision der fossilen Mystacoceten aus dem Tertiär Belgiens. Bulletin du Museum Royal d'Histoire Naturelles de Belgique 24(17):1-29.

Benke H. 1993. Investigations on the osteology and the functional morphology of the flipper of whales and dolphins (Cetacea). Investigations on Cetacea 24:9-252.

Bisconti M. 2000. New description, character analysis and preliminary phyletic assessment of two Balaenidae skulls from the Italian Pliocene. Palaeontographia Italica 87:37-66.

Bisconti M. 2002. An early late Pliocene right whale (Genus Eubalaena) from Tuscany (Central 1332 Italy). Bollettino della Società Paleontologica Italiana 4:83-91. 
1333 Bisconti M. 2003. Evolutionary history of Balaenidae. Cranium 20:9-50.

1334 Bisconti M. 2005a. Morphology and phylogenetic relationships of a new diminutive balaenid from 1335 the lower Pliocene of Belgium. Palaeontology 48:793-816.

1336 Bisconti M. 2005b. Paleontologia e conservazione: il caso della balena della Groenlandia. Pp. 133-

1337

1338

1339

1340

1341

1342

1343

1344

1345

1346

1347

1348

1349

1350

1351

1352

1353

1354

1355 142 in Scapini F. (ed.), La logica dell'evoluzione dei viventi - Spunti di Riflessione. Atti del XII Convegno del Gruppo Italiano di Biologia Evoluzionistica. Firenze University Press, Firenze, 167 pp.

Bisconti M. 2007. A new basal balaenopterid from the Early Pliocene of northern Italy. Palaeontology 50:1103-1122.

Bisconti M. 2008. Morphology and phylogenetic relationships of a new eschrichtiid genus (Cetacea: Mysticeti) from the Early Pliocene of northern Italy. Zoological Journal of the Linnean Society 153:161-186.

Bisconti M. 2011. New description of 'Megaptera' hubachi Dathe, 1983 based on the holotype skeleton held in the Museum für Naturkunde, Berlin. In: Bisconti M, Roselli A, Borzatti de Loewenstern A, eds. Climatic Change, Biodiversity, Evolution: Natural History Museum and Scientific Research. Proceedings of the Meeting. Quaderni del Museo di Storia Naturale di Livorno 23:37-68.

Bisconti M. 2012. Comparative osteology and phylogenetic relationships of Miocaperea pulchra, the first fossil pygmy right whale genus and species (Cetacea, Mysticeti, Neobalaenidae). Zoological Journal of the Linnean Society 166:876-911.

Bisconti M. 2015. Anatomy of a new cetotheriid genus and species from the Miocene of Herentals, Belgium, and the phylogenetic and paleobiogeographic relationships of Cetotheriidae s.s. (Mammalia, Cetacea, Mysticeti). Journal of Systematic Palaeontology 13:377-395. 
1356 Bisconti M, Bosselaers M. 2016. Fragilicetus velponi: a new mysticete genus and species and its 1357 implications for the origin of Balaenopteridae (Mammalia, Cetacea, Mysticeti). Zoological Journal of the Linnean Society 177:450-474.

1359

1360

1361

1362

1363

1364

1365

1366

1367

Bisconti M, Francou C. 2014. I cetacei fossili conservati presso il Museo Geologico di Castell'Arquato (PC). Museologia Scientifica Memorie 13:31-36.

Bisconti M, Lambert O, Bosselaers M. 2013. Taxonomic revision of Isocetus depawi (Mammalia, Cetacea, Mysticeti) and the phylogenetic relationships of archaic 'cetothere' mysticetes. Palaeontology 56:95-127.

Boessenecker R. 2011. New records of the fur seal Callorhinus (Carnivora: Otariidae) from the Plio-Pleistocene Rio Dell Formation of Northern California and comments on otariid dental evolution. Journal of Vertebrate Paleontology 31:454-467.

Boessenecker R. 2013. A new marine vertebrate assemblage from the Late Neogene Purisima Formation in Central California, part II: Pinnipeds and Cetaceans. Geodiversitas 35:815-940.

Boessenecker R, Fordyce RE. 2016. A new eomysticetid from the Oligocene Kokoamu Greensand of New Zealand and a review of the Eomysticetidae (Mammalia, Cetacea). Journal of Systematic Palaeontology. DOI: http://dx.doi.org/10.1080/14772019.2016.1191045.

Boessenecker RW, Fordyce RE. 2015. A new genus and species of eomysticetid (Cetacea: Mysticeti) and a reinterpretation of 'Mauicetus' lophocephalus Marples, 1956: transitional baleen whales from the Upper Oligocene of New Zealand. Zoological Journal of the Linnean Society. DOI: 10.1111/zoj.12297.

Brisson AD. 1762. Regnum animale in classes IX Distributum, sive synopsis methodica. Leiden: Theodorum Haak. 
1378 Chicchi S, Bisconti M. 2014. Valentina, una balena fossile nelle collezioni dei Musei Civici di 1379 Reggio Emilia. Museologia Scientifica Memorie 13:54-55.

1380 Churchill M, Berta A, Deméré TD. 2012. The systematics of right whales (Mysticeti: Balaenidae).

1381 Marine Mammal Science 28:497-521.

1382 Churchill M, Clementz MT, Kohno N. 2014. Predictive equations for the estimation of body size 1383 in seals and sea lions (Carnivora: Pinnipedia). Journal of Anatomy 225:232-245.

1384 Cioppi E. 2014. I cetacei fossili a Firenze, una storia lunga più di 250 anni. Museologia Scientifica Memorie 13:81-89.

1386

Clapham PJ, Young SB, Brownell RL Jr. 1999. Baleen whales: conservation issues and the status of the most endangered populations. Mammal Review 29:35-60.

Cope ED. 1891. Syllabus of Lectures on Geology and Paleontology. Philadelphia: Ferris Brothers. Cuvier G. 1823. Recherches sur les ossemens fossils. Paris: Chez Deterville.

Deméré TA, Berta A, McGowen MR. 2005. The taxonomic and evolutionary history of fossil and modern balaenopteroid mysticetes. Journal of Mammalian Evolution 12:99-143.

De Schepper S, Head MJ, Louwye S (2009). Pliocene dinoflagellate cyst stratigraphy, palaeoecology and sequence stratigraphy of the Tunnel-Canal Dock, Belgium. Geological magazine 146:92-112.

Desmoulins A. 1822. Baleine. Dictionnaire Classique d'Histoire Naturelle. Paris: Baudouin Frères.

Ehret DJ, Macfadden BJ, Jones DS, Devries TJ, Foster DA, Salas-Gismondi R. 2012. Origin of the white shark Carcharodon (Lamniformes: Lamnidae) based on recalibration of the Upper Neogene Pisco Formation of Peru. Palaeontology 55:1139-1153. 
1400 El Adli JJ, Deméré TA, Boessenecker RW. 2014. Herpetocetus morrowi (Cetacea: Mysticeti), a 1401 new species of diminutive baleen whale from the Upper Pliocene (Piacenzian) of California, USA, with observations on the evolution and relationships of the Cetotheriidae. Zoological Journal of the Linnean Society 170:400-466.

Evans AR, Jones D, Boyer AG, Brown JH, Costa DP, Morgan ESK, Fitzgerald EMG, Fortelius M, Gittleman JL, Hamilton MJ, Harding ME, Lintulaakso K, Kathleen Lyons S, Okie JG, Saarinen JJ, Sibly RM, Smith FA, Stephens PR, Theodor JM, Uhen MD. 2012. The maximum rate of mammal evolution. PNAS 109:4187-4190.

1408

1409

1410

1411

1412

1413

1414

1415

1416

1417

1418

1419

1420

1421

1422

Field DJ, Boessenecker R, Racicot RA, Ásbjörnsdóttir L, Jónasson K, Hsiang AY, Behlke AD, Vinther J. 2017. The oldest marine vertebrate fossil from the volcanic island of Iceland: a partial right whale skull from the high latitude Pliocene Tjörnes Formation. Palaeontology $60: 141-148$.

Fitch WM. 1971. Toward defining the course of evolution: minimum change for a specific tree topology. Systematic Zoology 20:406-416.

Flower WH. 1864. Notes on the skeletons of whales in the principal museums of Holland and Belgium, with descriptions of two species apparently new to science. Proceedings of the Zoological Society of London 1864:384-420.

Fordyce RE, de Muizon C. 2001. Evolutionary history of cetaceans: a review. Pp. 169-234 in J.M. Mazin and V. de Buffrenil (eds.). Secondary adaptation of tetrapods to life in water. Verlag Dr. Friedrich Pfeil, Munich.

Fortune SME, Trites AW, Perryman WL, Moore MJ, Pettis HM, Lynn MS. 2012. Growth and rapid early development of North Atlantic right whales (Eubalaena glacialis). Journal of Mammalogy 93:1342-1354. 
1423 Fraser FC, Purves PE. 1960. Hearing in cetaceans. Bulletin of the British Museum (Natural $1424 \quad$ History), Zoology 7:1-140.

1425 Gaines CA, Hare MP, Beck SE, Rosenbaum HC (2005) Nuclear markers confirm taxonomic status 1426 and relationships among highly endangered and closely related right whale species. 1427 Proceedings of the Royal Society of London. Series B, Biological Sciences 272:533-542.

1428 Gaskin DE. 1986. The ecology of whales and dolphins. London: Heineman.

1429 Geisler, J. \& Sanders, A. E. 2003. Morphological evidence for the phylogeny of Cetacea. Journal of Mammalian Evolution 10:23-129.

1431 George JC, Stimmelmayr R, Suydam R, Usip S, Givens G, Sformo T, Thewissen JGM. 2016. Severe bone loss as part of the life history strategy of bowhead whales. PLOS ONE 11(6): e0156753. DOI:10.1371/journal.pone.0156753.

Gol'din P, Startsev D, Krakhmalnaya T. 2014. The anatomy of the Late Miocene baleen whale Cetotherium riabinini from Ukraine. Acta Palaeontologica Polonica 59:795-814.

Gol'din P, Steeman ME. 2015. From problem taxa to problem solver: a new Miocene family, Tranatocetidae, brings perspective on baleen whale evolution. PLOS ONE 10(9):e0135500. DOI:10.1371/journal.pone.0135500.

Goloboff PA, Farris JS, Nixon KC. 2008. TNT, a free program for phylogenetic analysis. Cladistics 24:774-786.

Gray JE. 1864. On the Cetacea which have been observed in the seas surrounding the British 1443 Islands. Proceedings of the Scientific Meetings of the Zoological Society of London 1864:195248 
1444 Gray JE. 1825. Outline of an attempt at the disposition of the Mammalia into tribes and families 1445 with a list of the genera apparently appertaining to each tribe. Philosophical Annals 26:3371446344.

1447 Haile-Selassie Y, Melillo SM, Su DF. 2016. The Pliocene hominin diversity conundrum: do more 1448 fossils mean less clarity. Proceedings of the National Academy of Sciences USA 113:6364$1449 \quad 6371$.

1450 Hall BK. (ed.) 1996. Homology. Wiley, New York, 266 pp.

1451 Hasse G. 1909. Les morses du Pliocène poederlien à Anvers. Bulletin de la Société Belge de 1452 Géologie, de Paléontologie et d'Hydrogéologie 23:293-322.

1453 Heath T, Shannon A, Hedtke M, Hillis DM. 2008. Taxon sampling and the accuracy of 1454 phylogenetic analyses. Journal of Systematics and Evolution 46:239-257.

1455

1456

1457

1458 1459

1460 1461 1462 1463 1464 1465 1466
Heinzelin J de. 1950. Stratigraphie pliocene et quaternaire observée au Kruisschans. I. Analyse stratigraphique; II. Conclusions. Bulletin de l'Institut Royal des Sciences Naturelles de Belgique, 26(40-41):1-60.

Heinzelin J de. 1952. Note sur les coupes de l'écluse Baudouin à Anvers. Bulletin de la Société Belge de Géologie 61(1):106-108.

Heinzelin J de. 1955a. Considérations nouvelles sur le Néogène de l'Ouest de l'Europe. Bulletin de la Société Belge de Géologie 64:463-476.

Heinzelin J de. 1955b. Deuxième série d'observations stratigraphiques au Kruisschans. Coupes de l'écluse Baudouin. I. Analyse stratigraphique; II. Conclusions. Bulletin de l'Institut Royal des Sciences Naturelles de Belgique 31(66-67):1-43.

Huelsenbeck JP. 1994. Comparing the stratigraphic record to estimates of phylogeny. Paleobiology 20:470-483. 
1467 Jackson JA, Baker CS, Vant M, Steel DJ, Medrano-Gonzalez L, Palumbi SR. 2009. Big and slow:

1468 Estimates of molecular evolution in baleen whales (suborder Mysticeti). Molecular Biology 1469 and Evolution 26:2427-2440.

1470 Kaliszewska ZA, Seger J, Rowntree VJ, Barco SG, Benegas R, Best PB, Brown MW, Brownell 1471 RL Jr, Carribero A, Harcourt R, Knowlton AR, Marshalltilas K, Patenaude NJ, Rivarola M, 1472 Schaeff CM, Sironi M, Smith WA, Yamada TK. 2005. Population histories of right whales 1473 (Cetacea: Eubalaena) inferred from mitochondrial sequence diversities and divergences of 1474 their whale lice (Amphipoda: Cyamus). Molecular Ecology 14:3439-3456.

1475 Keane M, Semeiks J, Webb AE, Li YI, Quesada V, Craig T, Madsen LB, van Dam S, Brawand D, 1476 Marques PI, Michalak P, Kang L, Bhak J, Yim H-S, Grishin NV, Nielsen NH, Heide1477 Jørgensen MP, Oziolor EM, Matson CW, Church GM, Stuart GW, Patton JC, George JC, 1478 Suydam R, Larsen K, Lòpez-Otìn C, O’Connell MJ, Bickham JW, Thomsen B, de Magalhães JP. 2015. Insights into the Evolution of Longevity from the Bowhead Whale Genome. Cell Reports 10:112-122.

Kellogg R. 1928. The history of whales - their adaptation to life in the water. Quarterly Review of Biology 3:29-76; and 174-208.

Kenney RD. 2009. North Atlantic, North Pacific, and Southern right whales. In: Perrin WF, Wursig B, Thewissen JGM, eds. Encyclopedia of Marine Mammals. San Diego: Academic Press, 806-813.

Kimura T. 2009. Review of fossil balaenids from Japan with a re-description of Eubalaena 1487 shinshuensis (Mammalia, Cetacea, Mysticeti). Quaderni del Museo di Storia Naturale di Livorno 22:3-21. 
1489 Koshi WR, Davis RA, Miller GW, Withrow DE. 1993. Reproduction. In: Burns JJ, Montague JJ, 1490 Cowles CJ, eds. The bowhead whale. The Society for Marine Mammalogy Special Publication $1491 \quad 2: 239-274$.

1492 Laga P, Louwye S, Mostaert F. 2006. Disused Neogene and Quaternary regional stages from 1493 Belgium: Bolderian, Houthalenian, Antwerpian, Diestian, Deurnian, Kasterlian, 1494 Kattendijkian, Scaldisian, Poederlian, Merksemian and Flandrian. Geologica Belgica, 9:2151495 224.

1496

1497

1498

1499

1500

1501

1502

1503

1504

1505

1506

1507

1508

1509

1510

1511

Lambert O. 2008. A new porpoise (Cetacea, Odontoceti, Phocoenidae) from the Pliocene of the North Sea. Journal of Vertebrate Paleontology 28:863-872.

Linnaeus C. 1758. Systema Naturae. Stockholm: Salvii.

Louwye S, Head MJ, De Schepper S. 2004. Dinoflagellate cyst stratigraphy and palaeoecology of the Pliocene in northern Belgium, southern North Sea Basin. Geological Magazine 141:353378.

Maddison DR, Maddison WP. 2000. MacClade 4: Analysis of phylogeny and character evolution. Version 4.0. Sunderland: Sinauer Associates.

Malik, S., Brown, M.W., Kraus, S.D. \& B.N. White, 2000. Analysis of mitochondrial DNA diversity within and between North and South Atlantic right whales. Marine Mammal Science $16: 545-559$.

Manganelli G, Benocci A. 2014. I cetacei fossili del Museo dell'Accademia dei Fisiocritici di Siena. Museologia Scientifica Memorie 13:103-110.

Marquet R. 1993. The molluscan fauna of the Kruisschans Member (Lillo Formation, Late Pliocene) in the Antwerp area (Belgium). Contributions to Tertiary and Quaternary Geology 30:83-103. 
1512 Marx FG. 2011. The more the merrier? A large cladistics analysis of mysticetes, and comments on 1513 the transition from teeth to baleen. Journal of Mammalian Evolution 18:77-100.

1514 Marx FG, Fordyce RE 2015. Baleen boom and bust: a synthesis of mysticete phylogeny, diversity 1515 and disparity. Royal Society Open Science 2:140434.

1516 Marx FG, Fordyce RE. 2016. A link no longer missing: new evidence for the cetotheriid affinities of Caperea. PLOS ONE 11(10):e0164059. DOI:10.1371/journal.pone.0164059.

1518

1519

1520

1521

1522

1523

1524

1525

1526

1527

1528

1529

1530

1531

1532

1533

Smithsonian Contributions to Zoology 627:1-248.

Miller GS. 1923. The telescoping of the cetacean skull. Smithsonian Miscellaneous Collections $76: 1-70$.

Misonne X. 1958. Faune du Tertiaire et du Pléistocène inférieur de Belgique (Oiseaux et Mammifères). Bulletin de l'Institut Royal des Sciences Naturelles de Belgique 34(5):1-36.

Mitchell ED. 1989. A new cetacean from the late Eocene La Meseta Formation, Seymour Island, Antarctic Peninsula. Canadian Journal of Fisheries and Aquatic Sciences 46:2219-2235.

Moran MM, Bajpai S, George JC, Suydam R, Usip S, Thewissen JGM. 2014. Intervertebral and epiphyseal fusion in the postnatal ontogeny of cetaceans and terrestrial mammals. Journal of Mammalian Evolution 22:93-109.

Morgan GS. 1994. Miocene and Pliocene marine mammal faunas from the Bone Valley Formation of Central Florida. Proceedings of the San Diego Society of Natural History 29:239-268. 
1534 Nishiwaki M, Hasegawa Y. 1969. The discovery of the right whale skull in the Kisagata shell bed. 1535 The Scientific Reports of the Whale Research Institute Tokyo 21:79-84.

1536 Omura H. 1958. North Pacific right whale. The Scientific Reports of the Whale Research Institute 1537 Tokyo 13:1-52.

1538 Pastene LA, Goto M, Kanda N, Zerbini AN, Kerem D, Watanabe K, Bessho Y, Hasegawa M, 1539 Nielsen R, Larsen F, Palsbøll PJ. 2007. Radiation and speciation of pelagic organisms during 1540 periods of global warming: the case of the common minke whale, Balaenoptera acutorostrata. 1541 Molecular Ecology 16:1481-1495.

1542 Paul CRC. 1992. The recognition of ancestors. Historical Biology 6:239-250.

1543 Pivorunas A. 1979. The fibrocartilage skeleton and related structures of the ventral pouch of 1544 balaenopterid whales. Journal of Morphology 151:299-314.

1545 Plisnier-Ladame F, Quinet GE. 1969. Balaena belgica Abel 1938 Cetace du Merxemien d'Anvers. 1546 Bulletin de l'Institut Royal des Sciences Naturelles de Belgique 45(3):1-6.

1547 Pyenson ND, Sponberg SN. 2011. Reconstructing body size in extinct crown Cetacea (Neoceti) 1548 using allometry, phylogenetic methods, and tests from the fossil record. Journal of 1549 Mammalian Evolution 18:269-289.

1550 Quental TA, Marshall CR. 2010. Diversity dynamics: molecular phylogenies need the fossil 1551 record. Trends in Ecology and Evolution 25:434-441.

1552 Rice DW. 2009. Classification. In Perrin WF, Wursig B, Thewissen JGM eds. Encyclopedia of 1553 Marine Mammals. San Diego: Academic Press, 231-234.

1554 Rooney AP, Honeycutt RL, Derr JN. 2001. Population size change of Bowhead whales inferred 1555 from DNA sequence polymorphism data. Evolution 55:1678-1685. 
1556 Rosenbaum HC, Brownell RL Jr, Brown MW, Schaeff C, Portway V, White BN, Malik S, Pastene 1557 LA, Patenaude NJ, Baker CS, Goto M, Best PB, Clapham PJ, Hamilton P, Moore M, Payne

1558

1559

1560

1561

1562

1563

1564

1565

1566

1567

1568

1569

1570

1571

1572

1573

1574

1575

1576

1577

1578

R, Rowntree V, Tynan CT, Bannister JL, Salle RD. 2000. World-wide genetic differentiation of Eubalaena: questioning the number of right whale species. Molecular Ecology 9:17931802.

Sanderson LR, Wassersug R. 1993. Convergent and alternative designs for vertebrate suspension feeding. In: Hanken J, Hall BK eds. The skull. Vol. 3. Chicago: University Press of Chicago, $37-112$.

Santangelo G, Bisconti M, Santini F, Bramanti L 2005. Estinzioni e conservazione: il ruolo dei modelli nello studio e nella tutela della diversità biologica. Biology Forum 98:13-18.

Sarti C, Lanzetti A. 2014. I cetacei fossili del Museo Geologico Giovanni Capellini dell’Università di Bologna. Museologia Scientifica Memorie 13:70-78.

Sasaki T, Nikaido M, Hamilton H, Goto M, Kato H, Kanda N, Pastene LA, Cao Y, Fordyce RE, Hasegawa M, Okada N. 2005. Mitochondrial phylogenetics and evolution of mysticete whales. Systematic Biology 54:77-90.

Scannella JB, Fowler DW, Goodwin MB, Horner JR. 2014. Evolutionary trends in Triceratops from the Hell Creek Formation, Montana. Proceedings of the National Academy of Sciences USA 111:10245-10250.

Seehausen O. 2006. African cichlid fish: a model system in adaptive radiation research. Proceedings of the Royal Society B 273: DOI: 10.1098/rspb.2006.3539.

Shaller O. 1999. Nomenclatura anatomica veterinaria illustrate. Roma: Antonio Delfino Editore. Silva M, Downing JA. 1995. The allometric scaling of density and body mass: a nonlinear relationship for terrestrial mammals. The American Naturalist 145:704-727. 
1579 Steeman ME, Hebsgaard MB, Fordyce RE, Ho SYW, Rabosky DL, Nielsen R, Rahbek C, Glenner

1580 H, Sørensen MV, Willerslev E. 2009. Radiation of extant cetaceans driven by restructuring of 1581 the oceans. Systematic Biology 58:573-585.

1582 Tomilin AG. 1967. Cetacea. In: Heptner VG ed. Mammals of the USSR and adjacent countries. 1583 Vol. 9. Jerusalem: Israel Program for Scientific Translations, 1-717.

1584 Trites AD, Pauly D. 1998. Estimating mean body masses of marine mammals from maximum 1585 body lengths. Canadian Journal of Zoology 76:886-896. occurring in European waters; with some observations on the species of the north Pacific. Smithsonian Contributions to Knowledge 33:1-332.

1589

1590

Tsai C-H, Fordyce RE. 2015. Ancestor-descendant relationships in evolution: origin of the extant pygmy right whale, Caperea marginata. Biology Letters 11:20140875. DOI: http://dx.doi.org/10.1098/rsbl.2014.0875.

Uhen MD. 2008. New protocetid whales from Alabama and Mississippi, and a new cetacean clade, Pelagiceti. Journal of Vertebrate Paleontology 28:589-593.

Uhen MD, Gingerich PD. 2001. New genus of dorudontine archaeocete (Cetacea) from the middle-to-late Eocene of South Carolina. Marine Mammal Science 17:1-34.

Vandenberghe N, Laga P, Steurbaut E, Hardenbol J, Vail PR. 1998. Tertiary sequence stratigraphy at the southern border of the North Sea Basin in Belgium. Special Publication-SEPM, 60:119154.

Wagner PJ. 2000. Exhaustion of morphologic character states among fossil taxa. Evolution 54:365-386. 
1601 Yamada TK, Chou L-S, Chantrapornsyl S, Adulyanukosol K, Chakravarti SK, Oishi M, Wada S, 1602 Yao C-J, Kakuda T, Tajima Y, Arai K, Umetani A, Kurihara N. (2006). Middle sized 1603 balaenopterid whale specimens (Cetacea: Balaenopteridae) preserved at several institutions in 1604 Taiwan, Thailand, and India. Memoirs of the National Science Museum, Tokyo 44:1-10.

1605 Zachos J, Pagani M, Sloan L, Thomas E, Billups K. 2001. Trends, rhythms, and aberrations in 1606 global climate 65 Ma to present. Science 292:686-693.

1607

1608

1609

1610

1611 


\section{CAPTIONS TO TEXT-FIGURES AND TABLES}

1613

1614

1615

1616

1617

1618

1619

1620

1621

1622

1623

1624

1625

1626

1627

1628

1629

1630

1631

1632

1633

1634

\section{Figure 1}

Localities of the balaenids described in this paper. A, Localization of Antwerp in Belgium and its relationships with the North Sea. Grey whading represents marine Pliocene deposits. B, Detailed map of the Antwerp harbor showing the first Kruisschans lock, where the holotype of Eubalaena ianitrix sp. nov. (RBINS M. 879a-f) and the fragment of maxilla RBINS M. 880 were found. The cervical vertebrae RBINS M. 881 were discovered in the "Darses I-II" in Oorderen. Modified from De Schepper et al., 2009.

\section{Figure 2}

Lithological units from the Pliocene of the Antwerp area. Formations, members and their ages are provided, including the Kruisschans Sands Member of the Lillo Formation in the Piacenzian (Late Pliocene), where the neurocranium RBINS M. 879, holotype of Eubalaena ianitrix sp. nov., was discovered. Positions along the local lithostratigraphic column of other balaenid specimens from the Antwerp area investigated in this work are also provided: right maxilla RBINS M. 880, Balaenidae gen. et sp. indet.; cervical complex RBINS M. 881, Balaenidae gen. et sp. indet.; left humerus RBINS M. 2280, Eubalaena sp. Modified from De Schepper et al., 2009.

\section{Figure 3}

The cervical vertebrae RBINS M. 881 representing the cotype of 'Balaena' belgica by Abel (1941) and reassigned to Balaenidae gen. et sp. indet. in this work. A, anterior view. B, left lateral view. C, posterior view. D, right lateral view. E, ventral view. F, dorsal view. Scale bar equals $10 \mathrm{~cm}$. 
Figure 4

1639

The fragment of right maxilla RBINS M. 880 assigned to Balaenidae gen. et sp. indet. in this work.

A, dorsolateral view. B, dorsomedial view. C, ventromedial view. Scale bar equals $30 \mathrm{~cm}$.

1641

\section{Figure 5}

1643 The left humerus RBINS M. 2280 assigned to Eubalaena sp. in this work. A, lateral view. B, 1644 anterior view. C, distal view of articular facets for radius and ulna. D, proximal view or articular 1645 head for scapula. E, posterior view. F, medial view. Scale bars equal $10 \mathrm{~cm}$.

1646

\section{Figure 6}

1648 Eubalaena ianitrix sp. nov. (holotype RBINS M. 879). Dorsal view of neurocranium. A, 1649 photographic representation. B, interpretation. Scale bar equals $50 \mathrm{~cm}$. Anatomical abbreviations: $1650 \mathrm{fm}$, foramen magnum; fr, frontal; irfr, interorbital region of the frontal; oc, occipital condyles; smc, 1651 supramastoid crest; sq, squamosal; sop, supraorbital process of the frontal.

\section{Figure 7}

1654 Eubalaena ianitrix sp. nov. (holotype RBINS M. 879). Left lateral view of neurocranium. A, 1655 photographic representation. B, interpretation. Scale bar equals $50 \mathrm{~cm}$. Anatomical abbreviations: $1656 \mathrm{fm}$, foramen magnum; fr, frontal; irfr, interorbital region of the frontal; oc, occipital condyle; orb, 1657 orbit; otc, orbitotemporal crest; par, parietal; pgl, postglenoid process of squamosal; p-fr, parietal- 
1658 frontal suture; p-sq, parietal-squamosal suture; smc, supramastoid crest; soc, supraoccipital; sop, 1659 supraorbital process of frontal; sq, squamosal; vom, vomer; zyg, zygomatic process of squamosal; $1660 *$, anterolateral corner of parietal-frontal suture.

1661

1662

1663

1664 Figure 8

1665 Eubalaena ianitrix sp. nov. (holotype RBINS M. 879). Right lateral view of neurocranium. A, 1666 photographic representation. B, interpretation. Scale bar equals $50 \mathrm{~cm}$. Anatomical abbreviations:

1667 fm, foramen magnum; fr, frontal; irfr, interorbital region of the frontal; oc, occipital condyle; orb, 1668 orbit; otc, orbitotemporal crest; par, parietal; pgl, postglenoid process of squamosal; p-fr, parietal1669 frontal suture; p-sq, parietal-squamosal suture; smc, supramastoid crest; soc, supraoccipital; sop, 1670 supraorbital process of frontal; sq, squamosal; vom, vomer; zyg, zygomatic process of squamosal; $1671 *$, anterolateral corner of parietal-frontal suture.

1672

1673 Figure 9

1674 Eubalaena ianitrix sp. nov. (holotype RBINS M. 879). Anterior view of neurocranium. A, 1675 photographic representation. B, interpretation. Scale bar equals $50 \mathrm{~cm}$. Anatomical abbreviations: 1676 fr, frontal; irfr, interorbital region of the frontal; max-fr, grooves for articulation of maxilla and 1677 frontal; mes, mesethmoid; nas-fr, groove for articulation of nasal and frontal; pal, palatine; par, 1678 parietal; pgl, postglenoid process of squamosal; pm-fr, grooves for articulation of premaxilla and 1679 frontal; soc, supraoccipital; sop, supraorbital process of frontal; sq, squamosal; vom, vomer; zyg, 1680 zygomatic process of squamosal. 


\section{Figure 10.}

1683 Eubalaena ianitrix sp. nov. (holotype RBINS M. 879). Ventral view of neurocranium. A, 1684 photographic representation. B, interpretation. Scale bar equals $50 \mathrm{~cm}$. Anatomical abbreviations: 1685 exo, exoccipital; fm, foramen magnum; fr, frontal; sop, supraorbital process of frontal; oc, occipital 1686 condyle; och, optic channel; or, orbit; pgl, postglenoid process of squamosal; pt, pterygoid; sq, 1687 squamosal; vom, vomer; zyg, zygomatic process of squamosal.

\section{Figure 11}

1691

Eubalaena ianitrix sp. nov. (holotype RBINS M. 879). Posterior view of neurocranium. A, 1692 photographic representation. B, interpretation. Scale bar equals $50 \mathrm{~cm}$. Anatomical abbreviations: boc, basioccipital; bop, basioccipital protuberance; exo, exoccipital; fm, foramen magnum; fr, 1694 frontal; jn, jugular notch; oc, occipital condyle; pal, palatine; pgl, postglenoid process of squamosal; pt, pterygoid; ptf, pterygoid fossa; sop, supraorbital process of frontal; sq, squamosal; vom, vomer; zyg, zygomatic process of squamosal.

\section{Figure 12}

Phylogenetic relationships of Mysticeti with focus on Balaenoidea. Single most-parsimonious cladogram with the following tree statistics: Consistency Index (CI), 0.508; Retention Index (RI), (SCI), 0.825 . 


\section{Figure 13}

1705 Schematic representation of diagnostic characters observed in the holotype skull of Eubalaena 1706 ianitrix in left lateral view. Not to scale.

1707

1708

Figure 14

1709 Phylogenetic relationships of Balaenidae plotted against a time scale in million years (Ma). Bold 1710 lines represent stratigraphic ages of taxa based on dated specimens; light lines represent inferred 1711 presence of taxa. Note that three time periods are highlighted: (1) separation of Balaenidae and 1712 Neobalaenidae inferred to have occurred c. 11 Ma (latest Serravallian-to-earliest Tortonian); (2) 1713 separation of the Balaena + Balaenella clade and the Eubalaena + Balaenula clade inferred to 1714 have occurred c. $7 \mathrm{Ma}$ (latest Tortonian-to-earliest Messinian); and (3) origin of the extant 1715 Eubalaena species inferred to have occurred c. 2.5 Ma (latest Zanclean-to-earliest Piacenzian).

\section{Table 1}

Measurements (in mm) of RBINS M. 880 (cervical vertebrae complex, Balaenidae gen. et sp. indet.) and M. 2280 (left humerus, Eubalaena sp.). Characters are measured as preserved.

Table 2

1723 Measurements (in mm) of the neurocranium RBINS M. 879a-f (holotype of Eubalaena ianitrix 1724 sp. nov.). Characters are measured as preserved. 


\section{Figure 1}

Fig. 1 - Localities of the balaenids described in this paper.

A, Localization of Antwerp in Belgium and its relationships with the North Sea. Grey whading represents marine Pliocene deposits. B, Detailed map of the Antwerp harbor showing the first Kruisschans lock, where the holotype of Eubalaena ianitrix sp. nov. (RBINS M. 879a-f) and the fragment of maxilla RBINS M. 880 were found. The cervical vertebrae RBINS M. 881 were discovered in the "Darses I-II" in Oorderen. Modified from De Schepper et al., 2009. 


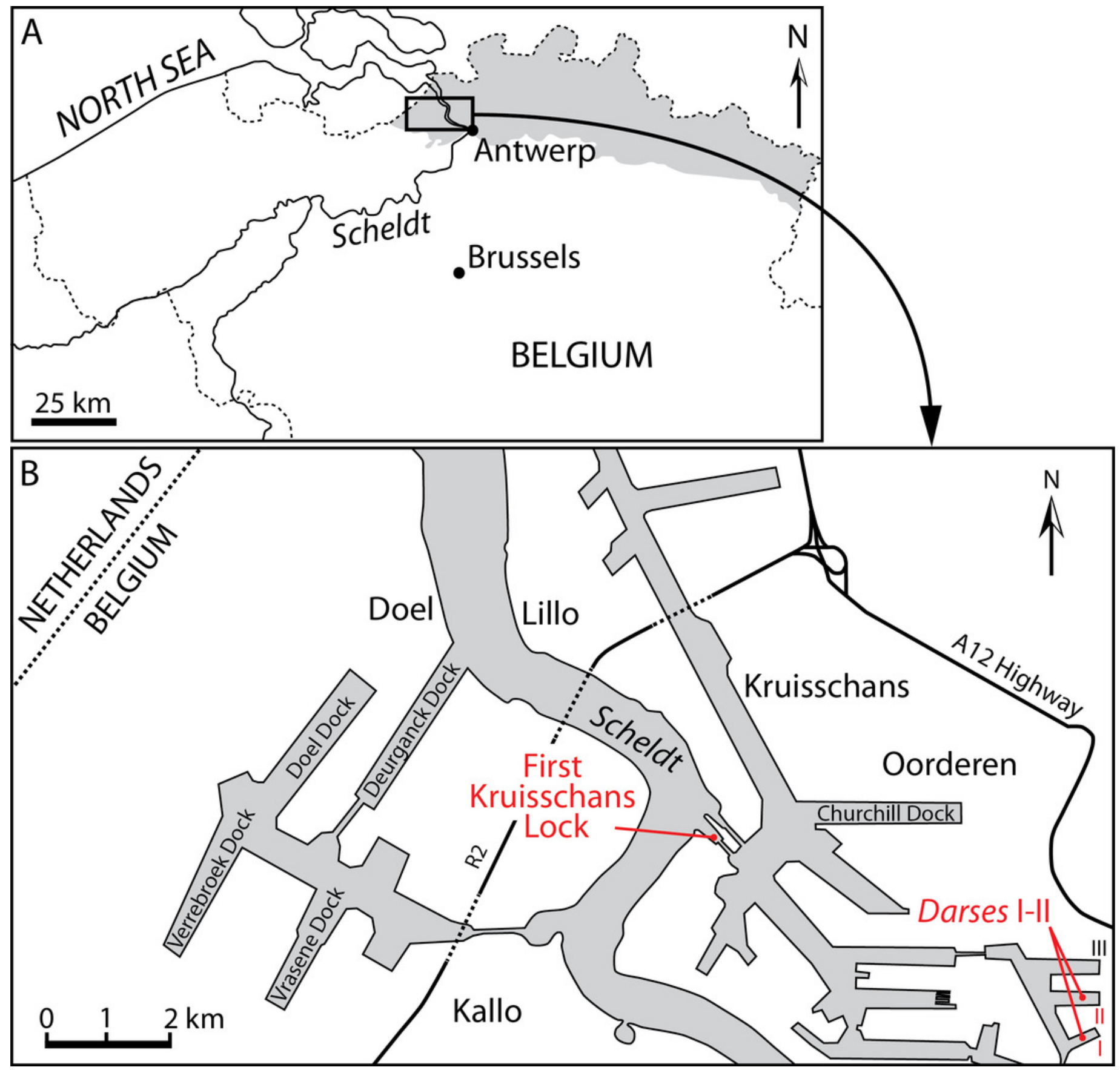


Figure 2

Fig. 2 - Lithological units from the Pliocene of the Antwerp area.

Formations, members and their ages are provided, including the Kruisschans Sands Member of the Lillo Formation in the Piacenzian (Late Pliocene), where the holotype of Eubalaena ianitrix sp. nov. was discovered. Modified from De Schepper et al., 2009.

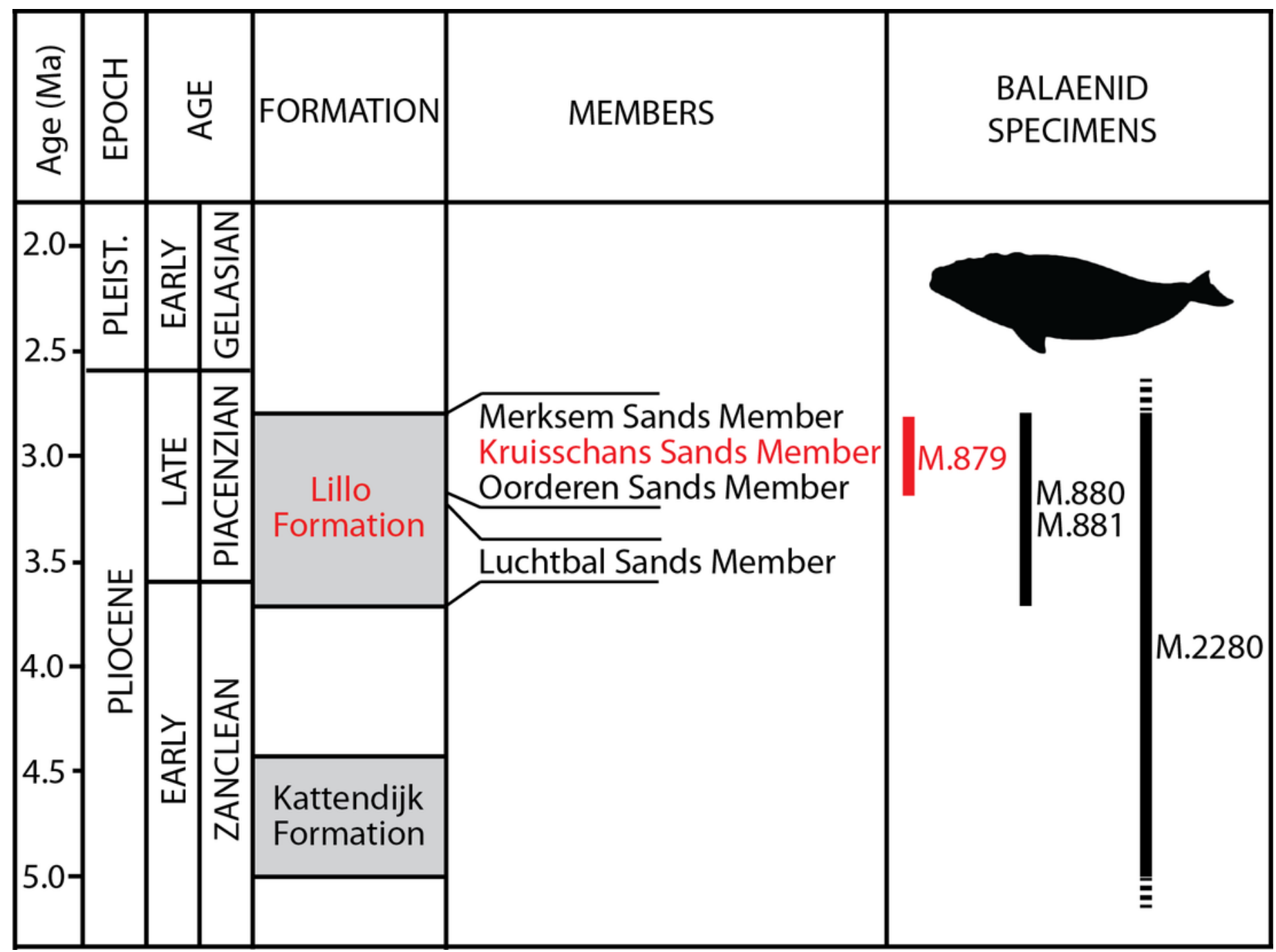




\section{Figure 3}

Fig. 3 - The cervical vertebrae RBINS M. 881 that were originally used as type of 'Balaena' belgica by Abel (1941) and reassigned to Balaenidae gen. et sp. indet. in this work.

A, anterior view. B, left lateral view. C, posterior view. D, right lateral view. E, ventral view. F, dorsal view. Scale bar equals $10 \mathrm{~cm}$. 

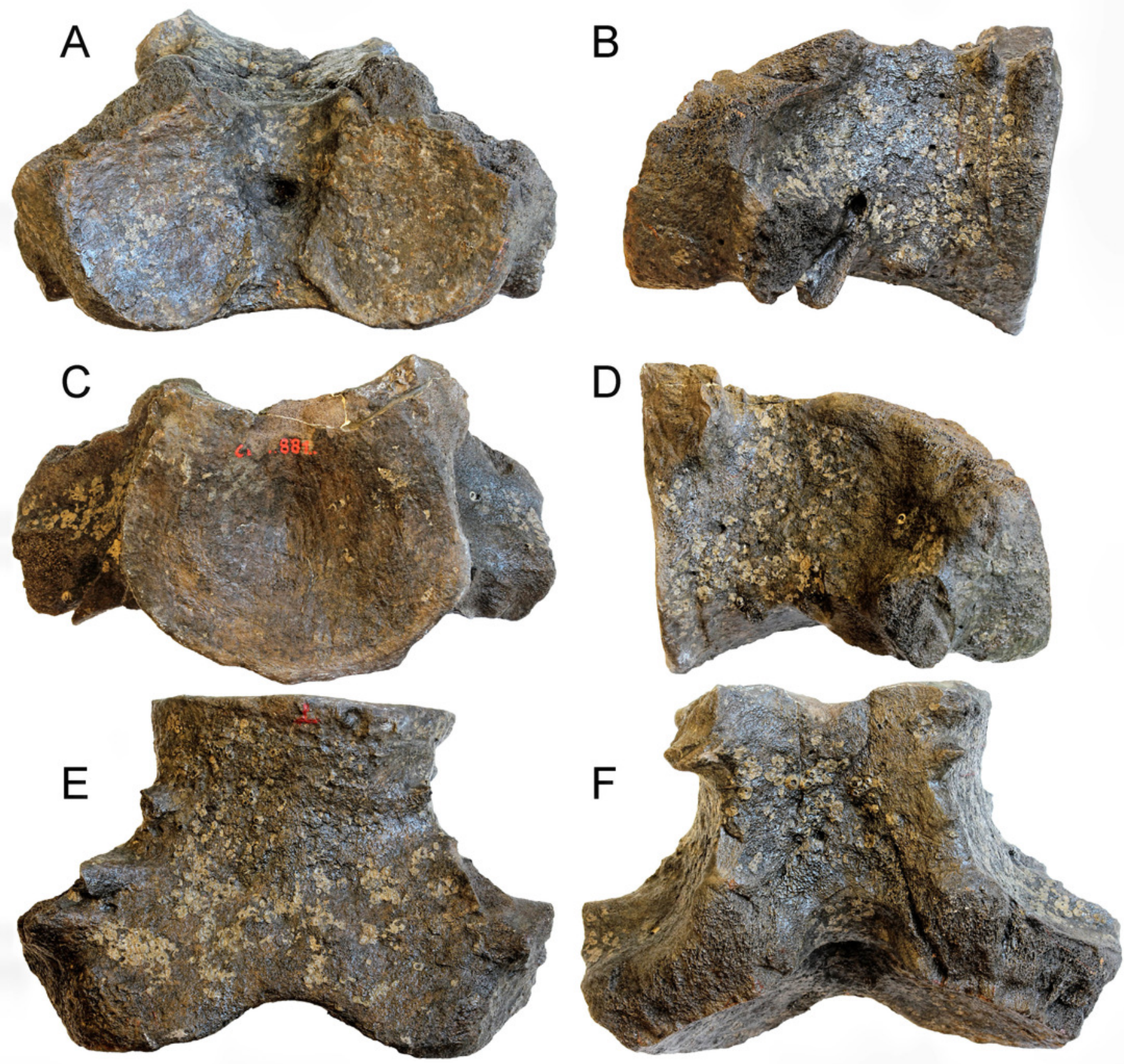


\section{Figure 4}

Fig. 4 - The fragment of right maxilla RBINS M. 880 assigned to Balaenidae gen. et sp. indet. in this work.

A, dorsolateral view. B, dorsomedial view. C, ventromedial view. Scale bar equals $30 \mathrm{~cm}$.

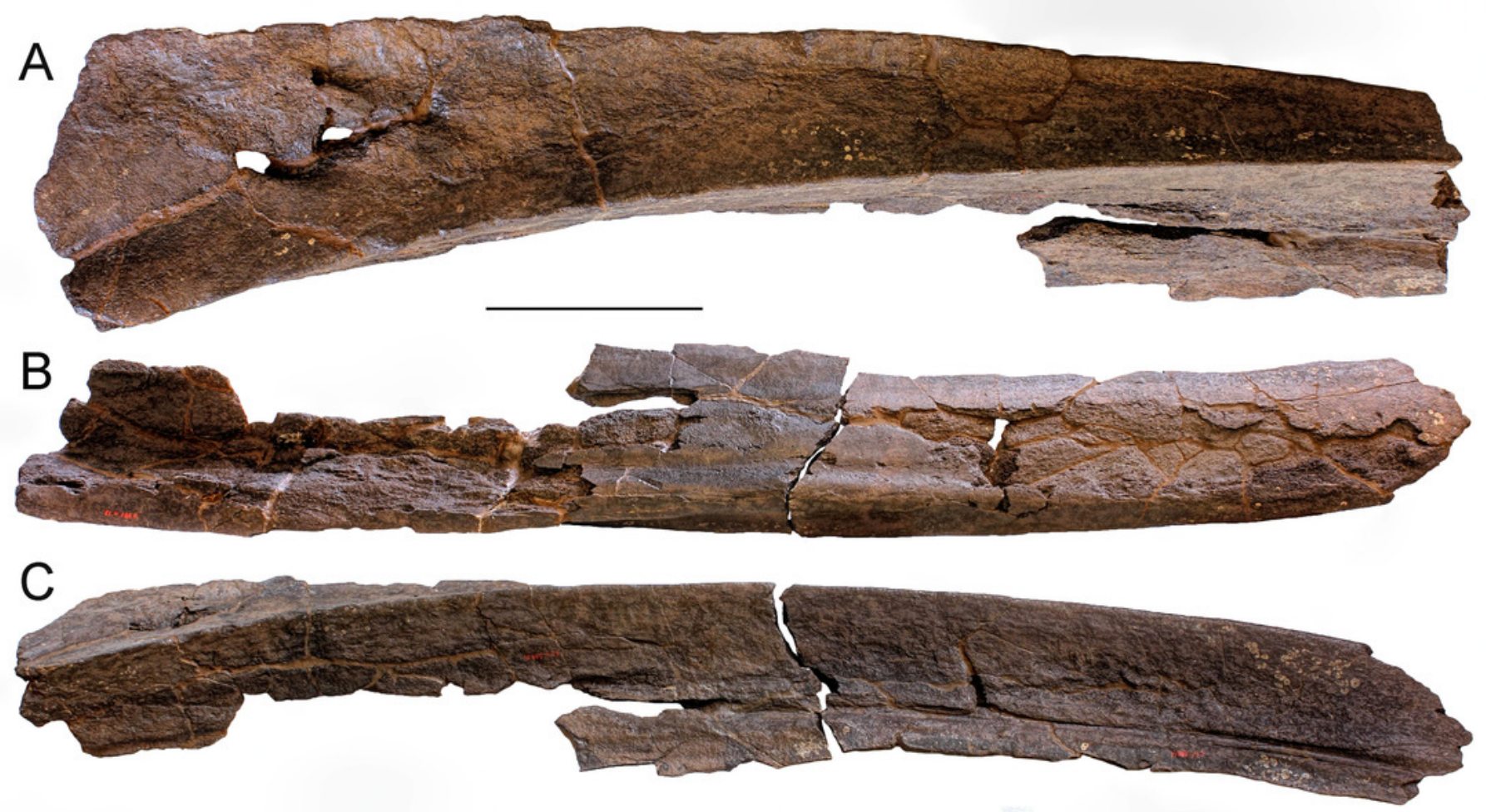




\section{Figure 5}

Fig. 5 - The left humerus RBINS M. 2280 assigned to Eubalaena sp. in this work.

A, lateral view. B, anterior view. C, distal view of articular facets for radius and ulna. D, proximal view or articular head for scapula. E, posterior view. F, medial view. Scale bars equal $10 \mathrm{~cm}$.
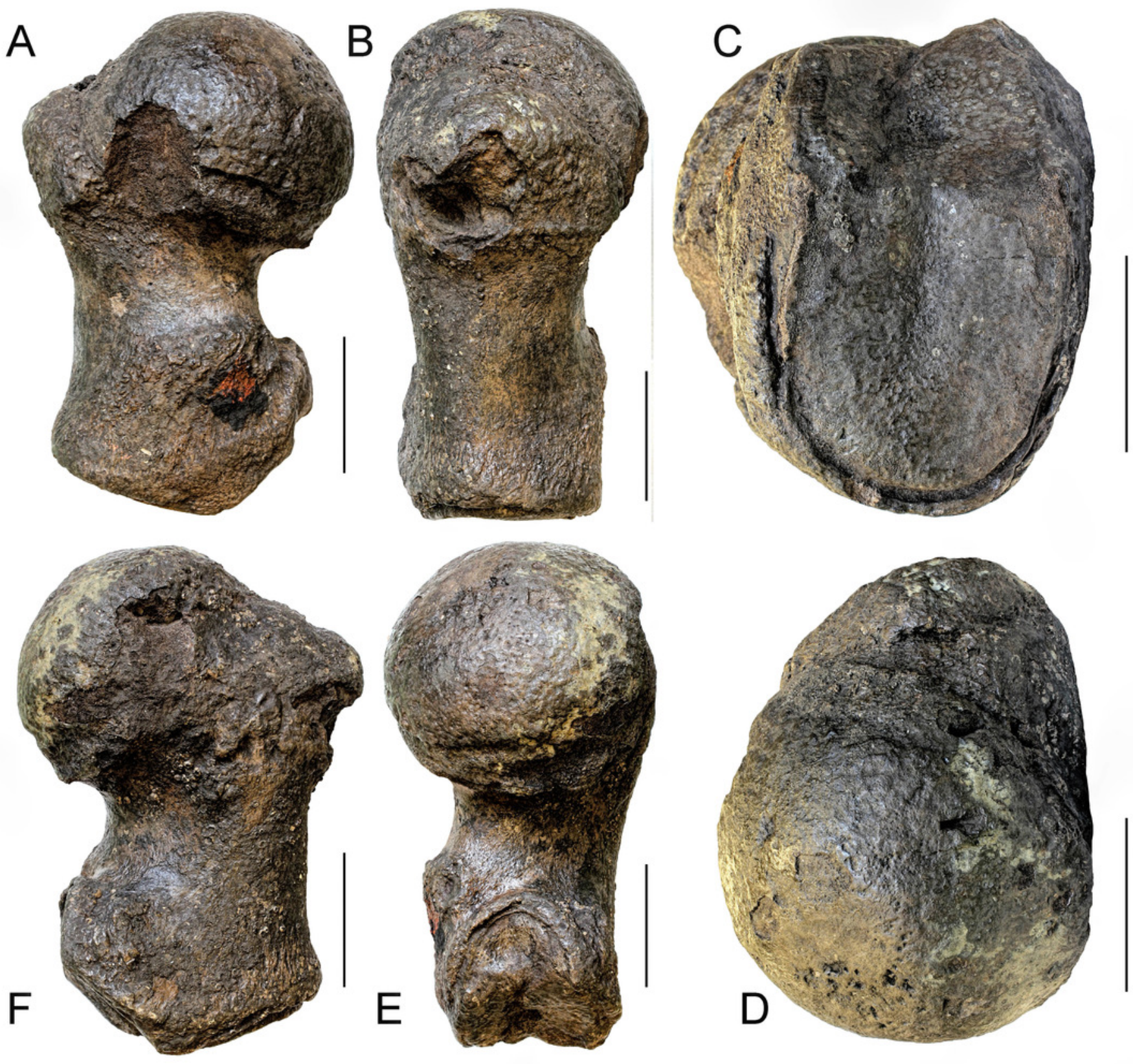


\section{Figure 6}

Fig. 6 - Eubalaena ianitrix sp. nov. (holotype RBINS M. 879). Dorsal view of neurocranium.

A, photographic representation. B, interpretation. Scale bar equals $50 \mathrm{~cm}$. Anatomical abbreviations: fm, foramen magnum; fr, frontal; irfr, interorbital region of the frontal; oc, occipital condyles; smc, supramastoid crest; sq, squamosal; sop, supraorbital process of the frontal.
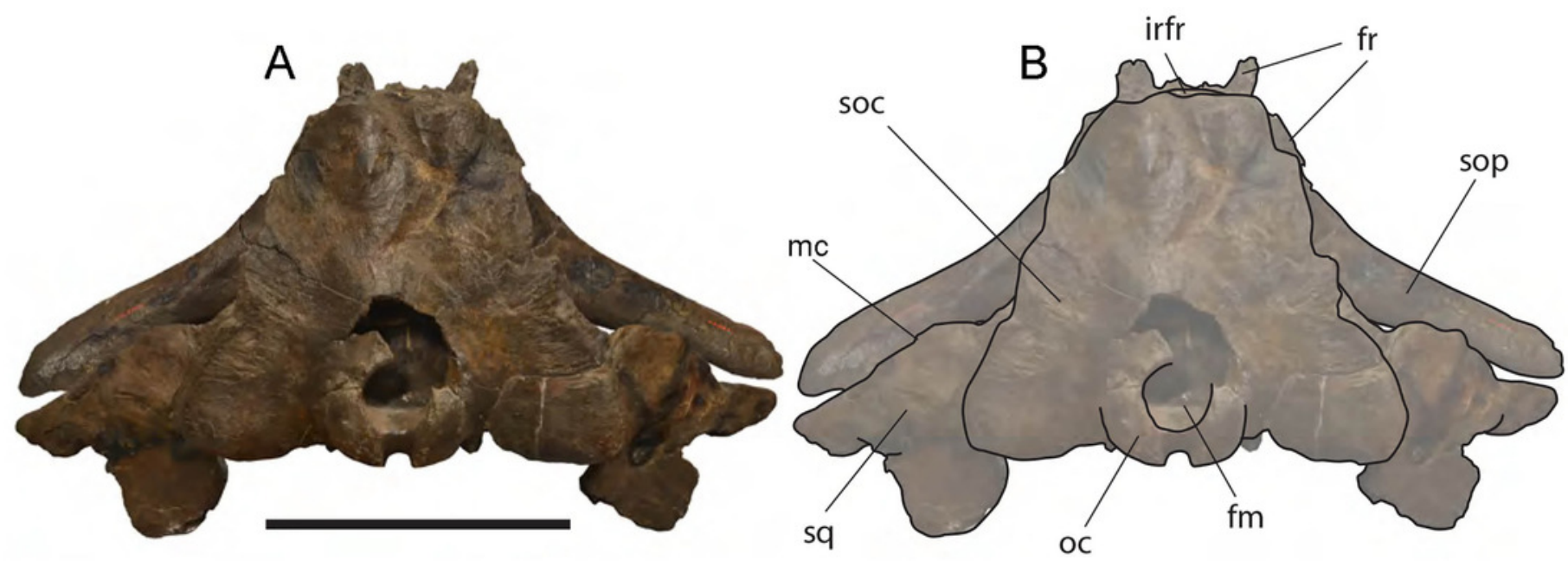


\section{Figure 7}

Fig. 7 - Eubalaena ianitrix sp. nov. (holotype RBINS M. 879). Left lateral view of neurocranium.

A, photographic representation. B, interpretation. Scale bar equals $50 \mathrm{~cm}$. Anatomical abbreviations: fm, foramen magnum; fr, frontal; irfr, interorbital region of the frontal; oc, occipital condyle; orb, orbit; otc, orbitotemporal crest; par, parietal; pgl, postglenoid process of squamosal; p-fr, parietal-frontal suture; p-sq, parietal-squamosal suture; smc, supramastoid crest; soc, supraoccipital; sop, supraorbital process of frontal; sq, squamosal; vom, vomer; zyg, zygomatic process of squamosal; *, anterolateral corner of parietal-frontal suture.

A

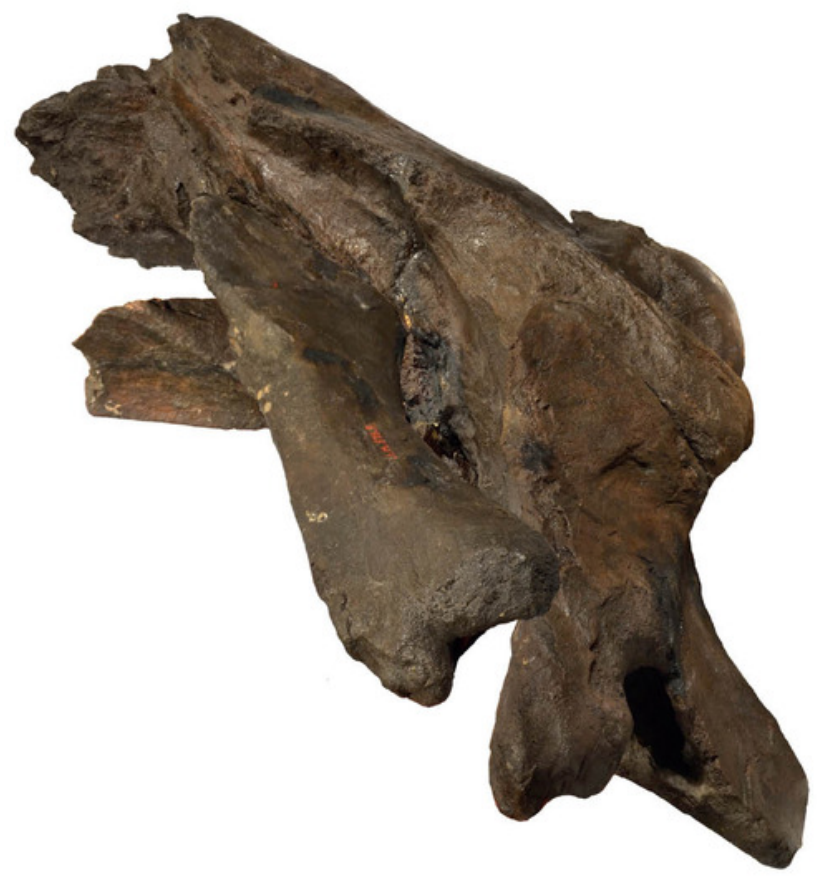

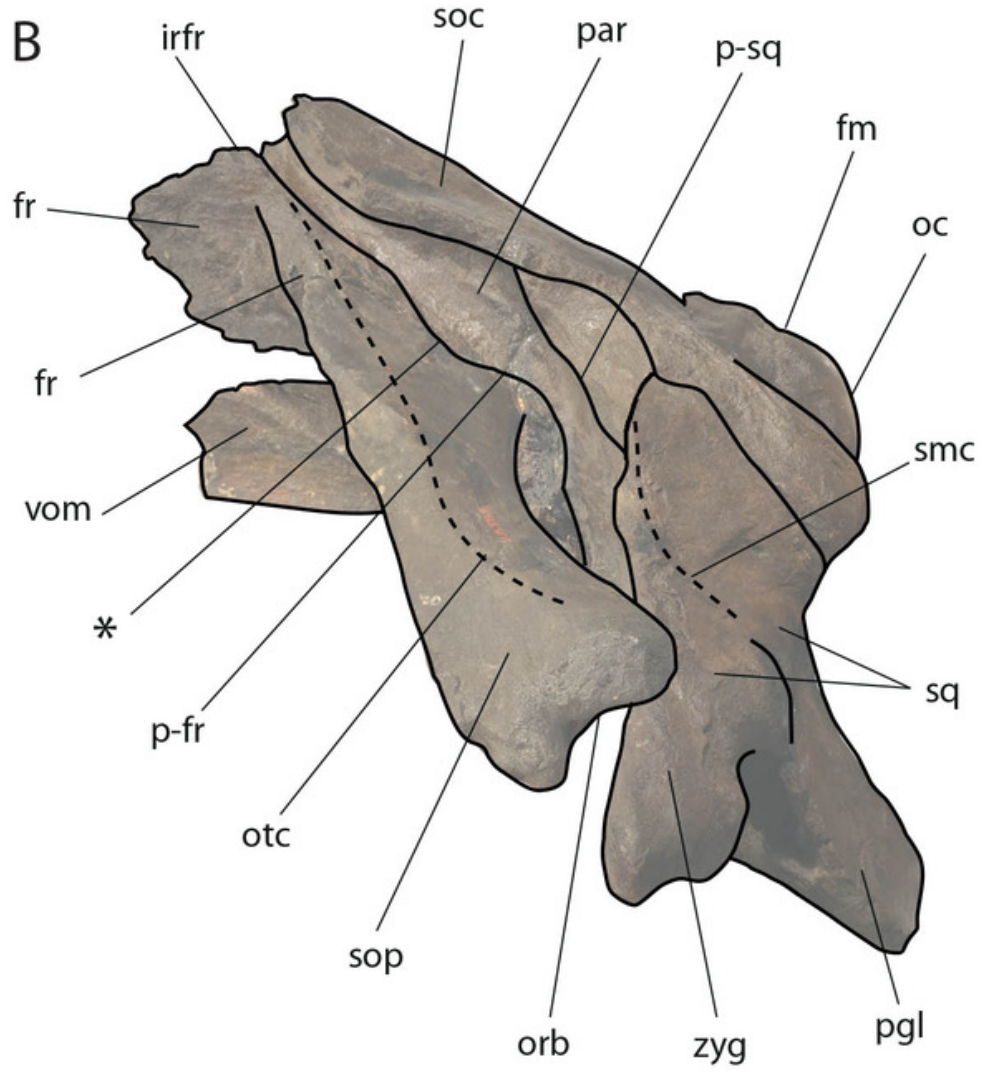




\section{Figure 8}

Fig. 8 - Eubalaena ianitrix sp. nov. (holotype RBINS M. 879). Right lateral view of neurocranium.

A, photographic representation. B, interpretation. Scale bar equals $50 \mathrm{~cm}$. Anatomical abbreviations: fm, foramen magnum; fr, frontal; irfr, interorbital region of the frontal; oc, occipital condyle; orb, orbit; otc, orbitotemporal crest; par, parietal; pgl, postglenoid process of squamosal; p-fr, parietal-frontal suture; p-sq, parietal-squamosal suture; smc, supramastoid crest; soc, supraoccipital; sop, supraorbital process of frontal; sq, squamosal; vom, vomer; zyg, zygomatic process of squamosal; *, anterolateral corner of parietal-frontal suture.

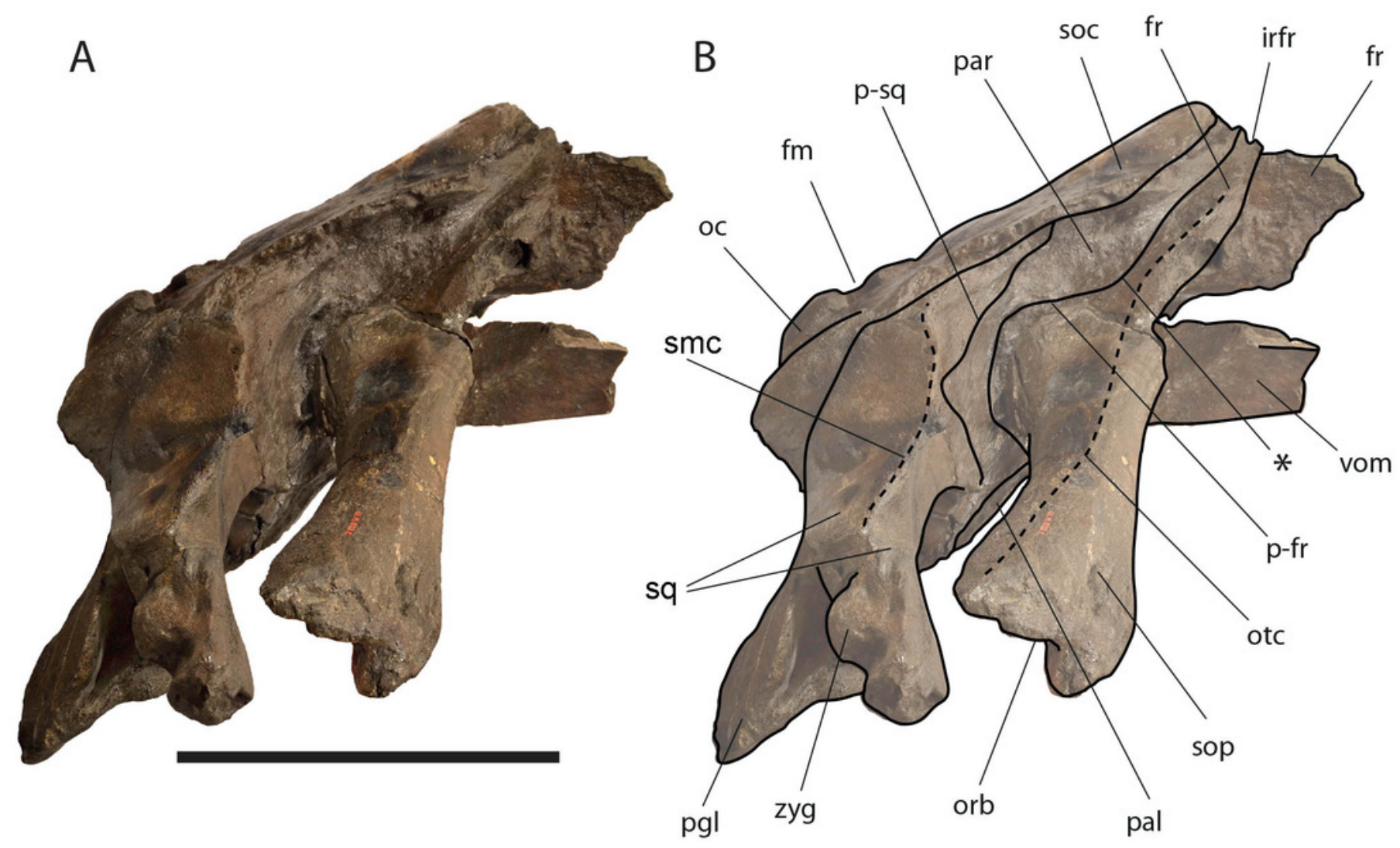




\section{Figure 9}

Fig. 9 - Eubalaena ianitrix sp. nov. (holotype RBINS M. 879). Anterior view of neurocranium.

A, photographic representation. B, interpretation. Scale bar equals $50 \mathrm{~cm}$. Anatomical abbreviations: fr, frontal; irfr, interorbital region of the frontal; max-fr, grooves for articulation of maxilla and frontal; mes, mesethmoid; nas-fr, groove for articulation of nasal and frontal; pal, palatine; par, parietal; pgl, postglenoid process of squamosal; pm-fr, grooves for articulation of premaxilla and frontal; soc, supraoccipital; sop, supraorbital process of frontal; sq, squamosal; vom, vomer; zyg, zygomatic process of squamosal.

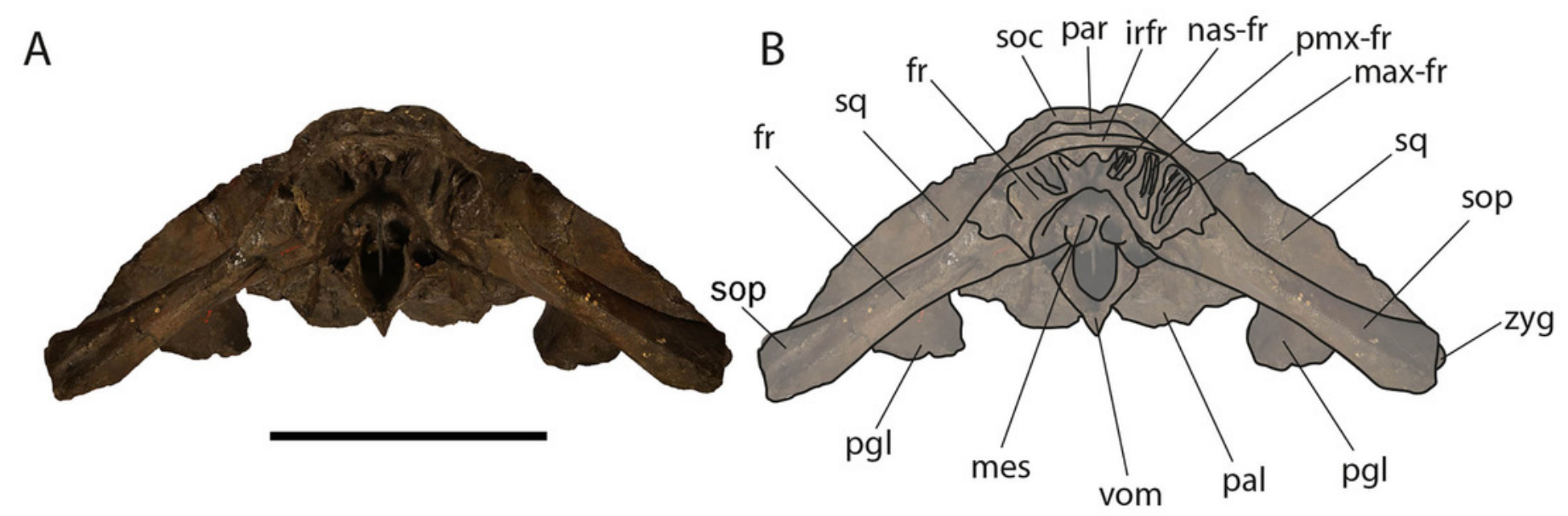




\section{Figure 10}

Fig. 10 - Eubalaena ianitrix sp. nov. (holotype RBINS M. 879). Ventral view of neurocranium.

A, photographic representation. B, interpretation. Scale bar equals $50 \mathrm{~cm}$. Anatomical abbreviations: exo, exoccipital; fm, foramen magnum; fr, frontal; sop, supraorbital process of frontal; oc, occipital condyle; och, optic channel; or, orbit; pgl, postglenoid process of squamosal; pt, pterygoid; sq, squamosal; vom, vomer; zyg, zygomatic process of squamosal.
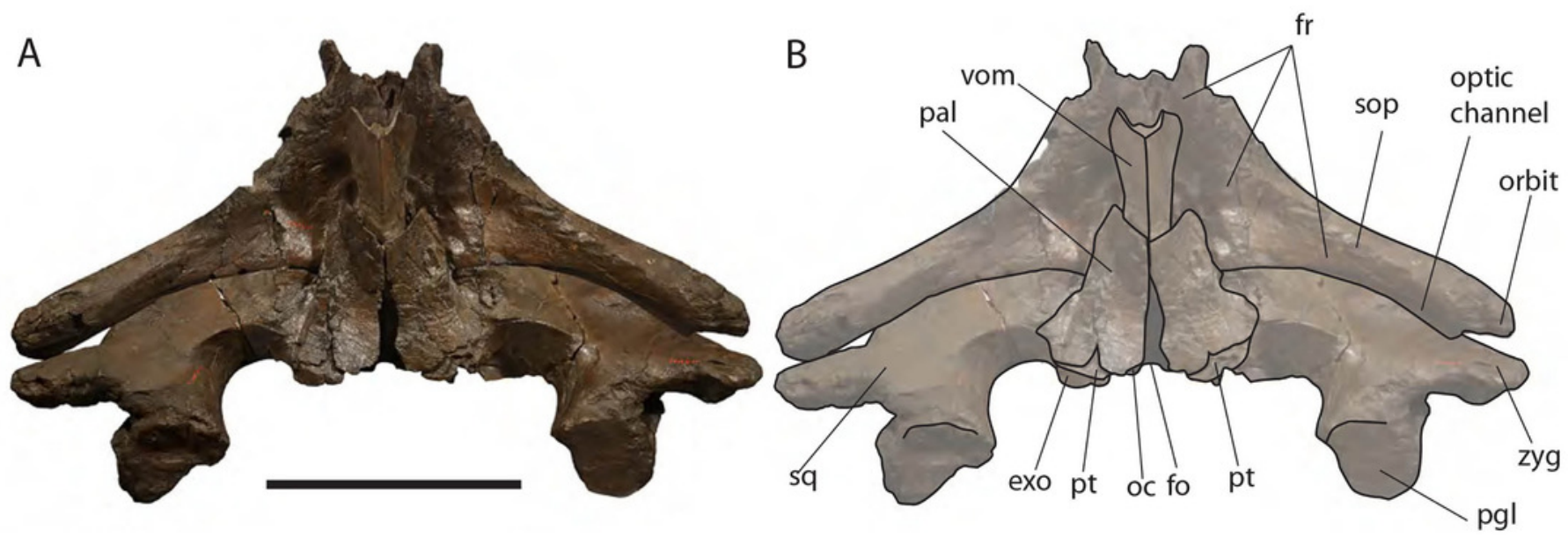


\section{Figure 11}

Fig. 11 - Eubalaena ianitrix sp. nov. (holotype RBINS M. 879). Posterior view of neurocranium.

A, photographic representation. B, interpretation. Scale bar equals $50 \mathrm{~cm}$. Anatomical abbreviations: boc, basioccipital; bop, basioccipital protuberance; exo, exoccipital; fm, foramen magnum; fr, frontal; jn, jugular notch; oc, occipital condyle; pal, palatine; pgl, postglenoid process of squamosal; pt, pterygoid; ptf, pterygoid fossa; sop, supraorbital process of frontal; sq, squamosal; vom, vomer; zyg, zygomatic process of squamosal.

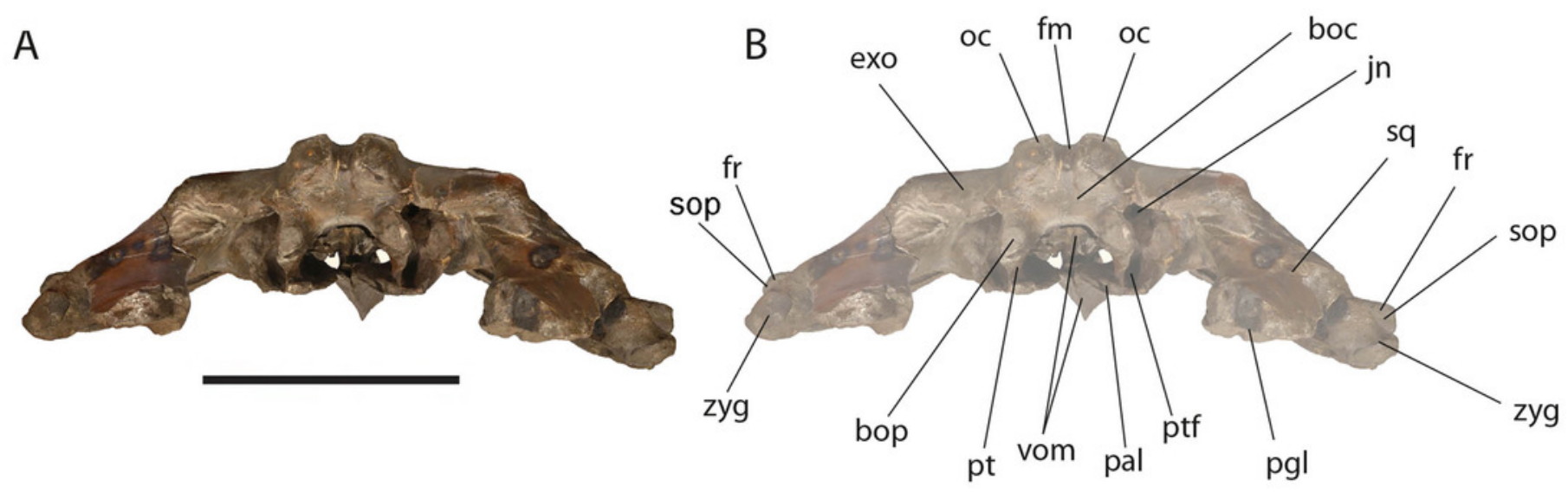




\section{Figure 12}

Fig. 12 - Phylogenetic relationships of Mysticeti with focus on Balaenoidea.

Single most-parsimonious cladogram with the following tree statistics: Consistency Index (Cl), 0.508; Retention Index (RI), 0.805; Rescaled $\mathrm{Cl}, 0.40894$; Homoplasy Index (HI), 0.492; Stratigraphic Consistency Index (SCl), 0.825 . 


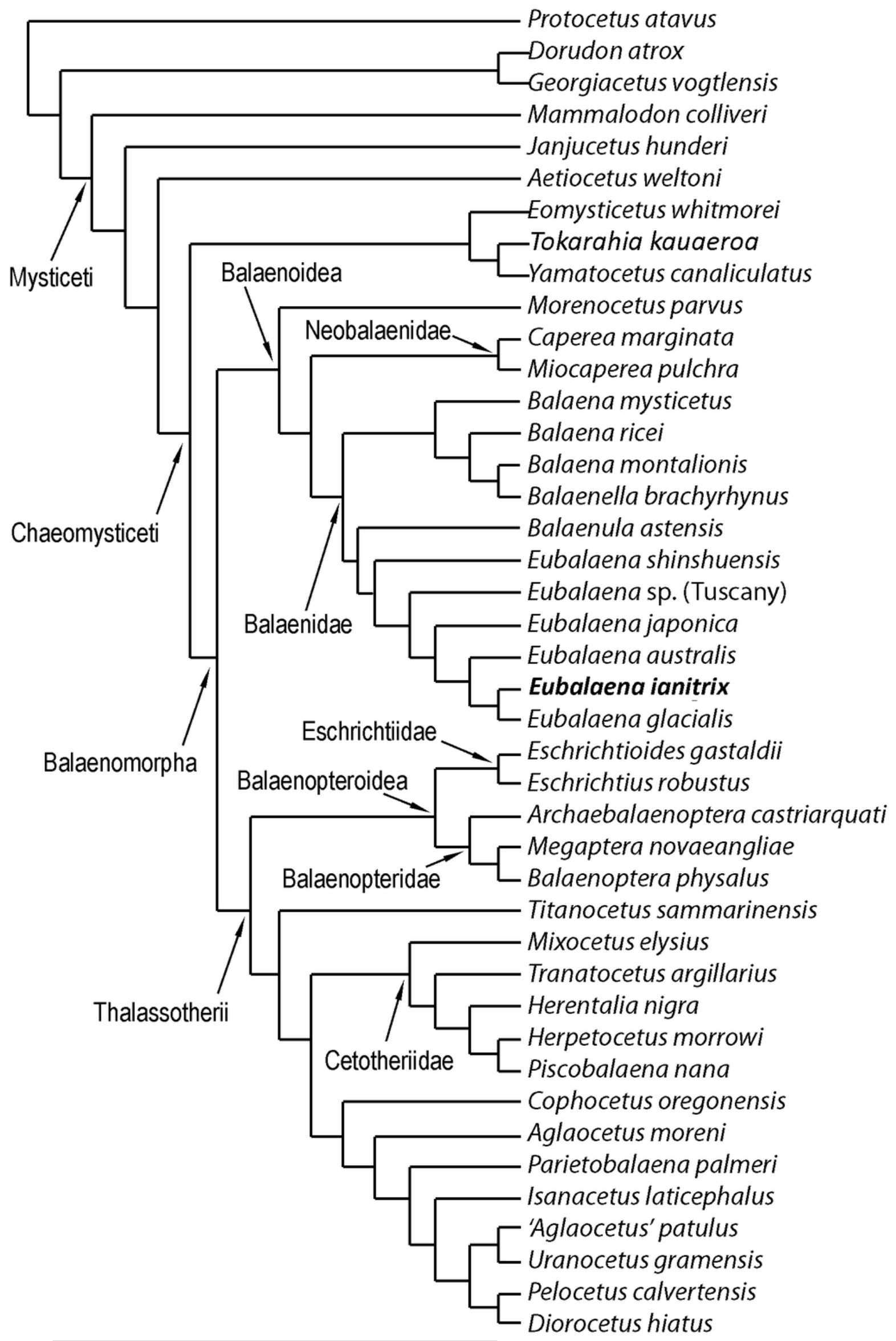




\section{Figure 13}

Fig. 13 - Schematic representation of diagnostic characters observed in the holotype skull of Eubalaena ianitrix in left lateral view.

Not to scale.

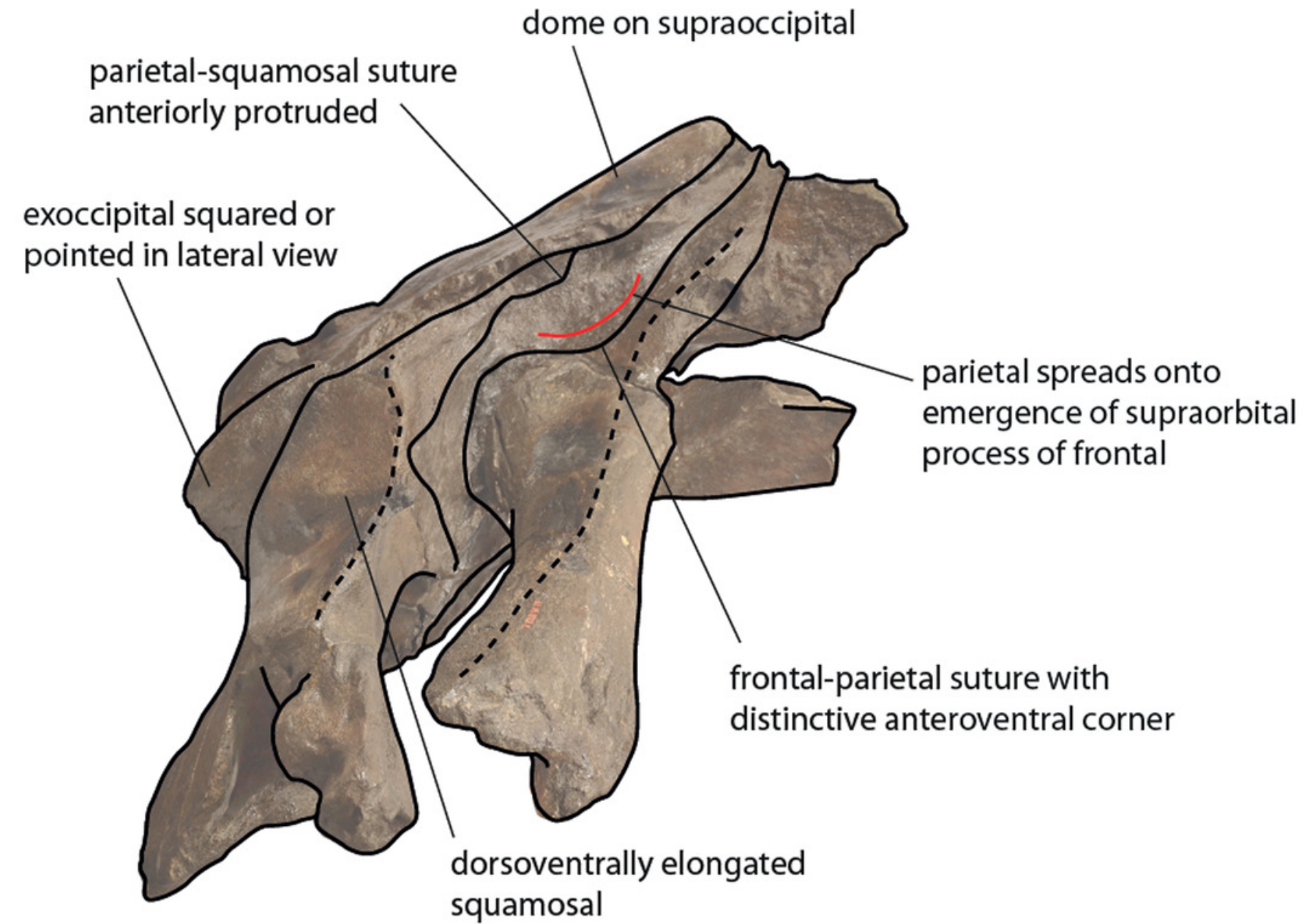




\section{Figure 14}

Phylogenetic relationships of Balaenidae plotted against temporal scale

Fig 14 - Phylogenetic relationships of Balaenidae plotted against a temporal scale showing that the separation of Balaenidae and Neobalaenidae occurred before Tortonian at least and that the separation of the Balaena + Balaenella clade from the Eubalaena + Balaenula clade occurred at the beginning or during the Messinian (latest Miocene). The origin of the modern Eubalaena (right whale) is inferred to be occurred at the beginning of the Piacenzian.

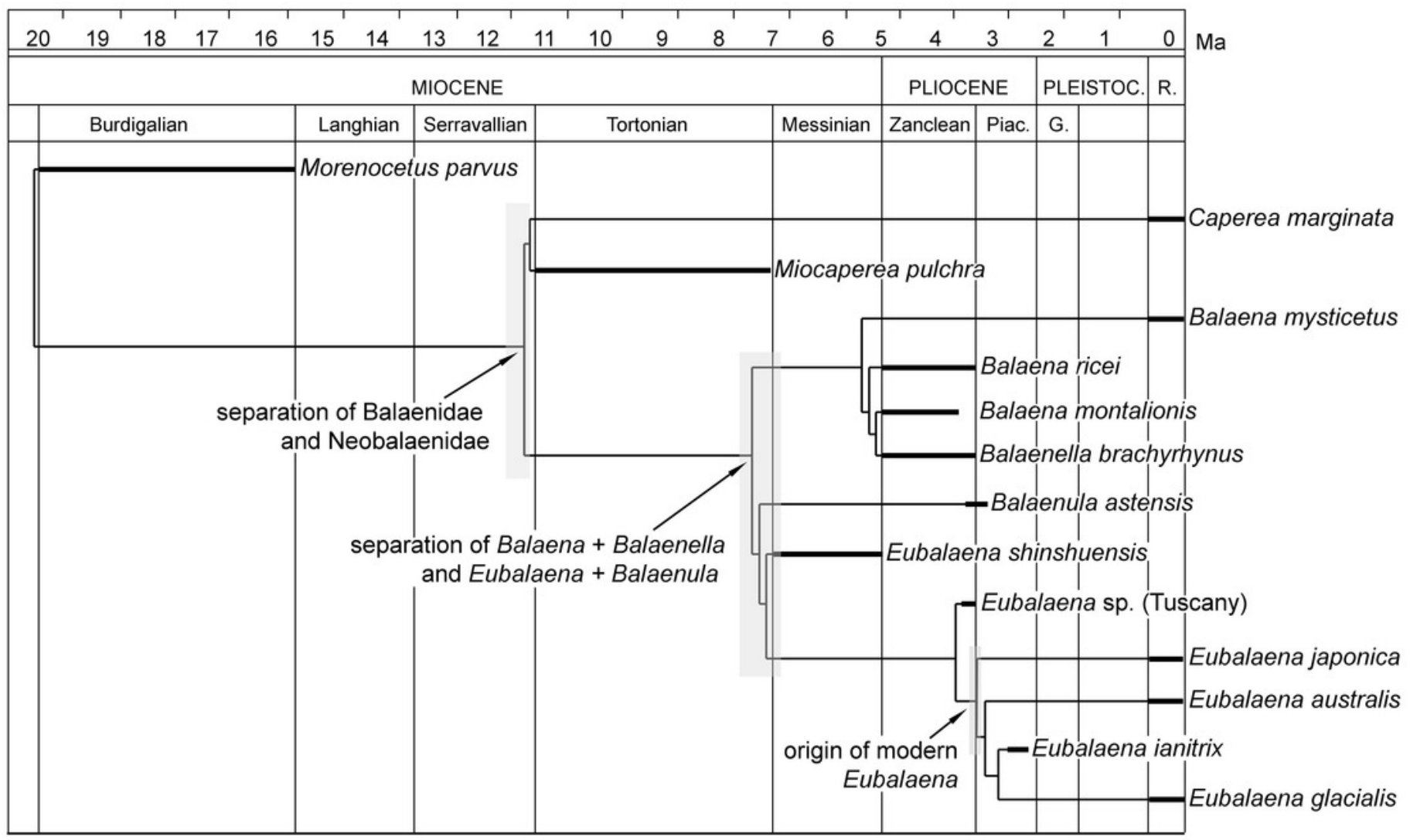




\section{Table $\mathbf{1}$ (on next page)}

Table 1 - Measurements (in mm) of RBINS M. 880 (cervical vertebrae complex, Balaenidae gen. et sp. indet.) and M. 2280 (left humerus, Eubalaena sp.).

Characters are measured as preserved. 
$1 \quad$ Table 1

2 Measurements (in mm) of RBINS M. 880 (cervical vertebrae) and M. 2280 (left humerus).

3 Characters are measured as preserved.

4

\begin{tabular}{lc}
\hline Character & Measure \\
\hline & \\
M. 880 (cervical vertebrae) & 280 \\
maximum anteroposterior length of whole complex & 423 \\
maximum transverse width of whole complex & 384 \\
maximum width across articular facets of atlas & 175 \\
maximum height of articular facets of atlas & 246 \\
posterior width of centrum of last cervical & 201 \\
posterior height of centrum of last cervical & \\
& \\
M. 2280 (left humerus) & 683 \\
total length & 355 \\
maximum proximal mediolateral width & 458 \\
maximum proximal anteroposterior width & 345 \\
anteroposterior diameter of humeral head & 343 \\
mediolateral diameter of humeral head & 222 \\
minimum mediolateral width of diaphysis & 271 \\
minimum anteroposterior width of diaphysis & 249 \\
distal mediolateral width & 364 \\
maximum distal anteroposterior width & 239 \\
anteroposterior length of radial facet & 250 \\
anteroposterior length of ulnar facet (including facet for olecranon) & \\
\hline
\end{tabular}

5

6

7

8 


\section{Table 2 (on next page)}

Table 2 - Measurements (in mm) of the neurocranium RBINS M. 879a-f (holotype of Eubalaena ianitrix sp. nov.).

Characters are measured as preserved. 


\section{Table 2}

2 Measurements (in mm) of the neurocranium RBINS M. 879a-f (holotype of Eubalaena ianitrix

3 sp. nov.). Characters are measured as preserved.

4

Character $\quad$ Measure

bizygomatic width

1660

estimated postorbital width

1760

width of occipital condyles

290

distance between lateral margins of exoccipitals

850

length of supraoccipital shield from foramen magnum to vertex $\quad 560$

height between basicranium and vertex

71

transverse width of maxillae at vertex

290

5

6

7

8

9

10

11

12 